\title{
La formación del contrato en la Convención de Viena de 1980
}

\author{
José Leyva Saavedra \\ Pilar Perales Viscasillas
}

\section{Nota introductoria}

No cabe duda que, hasta el momento, el más grande suceso registrado con respecto a la unificación o armonización del derecho lo constituye la disciplina de la compraventa internacional ${ }^{1}$, contenida en la Convención de Viena sobre los contratos de compraventa internacional de mercaderías de 1980. Por ser el contrato comercial por excelencia y la columna vertebral de todo el sistema de las relaciones económicas ${ }^{2}$, la compraventa estaba llamada a convertirse en el más importante vehículo del intercambio de mercancías o, si se prefiere, en el motor del desarrollo del comercio internacional ${ }^{3}$. Para allanarle el camino, no se

1 Leyva Saavedra, "Contratos de empresa", en Tratado de derecho privado, Lima, 1997, vol. II, t. 1, p. 133; Id., "La Convención de Viena sobre la compraventa internacional», en Cathedra, Lima, 1999, N 5, p. 165.

2 Cfr. Galgano, Il diritto privato fra codice e costituzione, Bologna, 1980, p. 6; Memmo, "Il contratto di vendita internazionale nel diritto uniforme", en Rivista trimestrale di diritto e procedura civile, Milano, 1983, No 1, p. 181; Ferrari, "Ĺambito di applicazione della convenzione di vienna sulla vendita internazionale», en Rivista trimestrale di diritto e procedura civile, Milano, 1994, No 3, p. 898.

3 La importancia de la compraventa internacional, desde un punto de vista económico, es tan evidente que no requiere mayor mención; baste recordar que es el instrumento a través del cual se realiza una gran parte del comercio internacional, apunta López de Gozalo, "La vendita internazionale», en Alpa - Bessone (dirs.), I contratti in generale. Contratti atipici, Torino, 1991, vol. II, t. 2, p. 903 . No sólo es importante la Convención por el elevado volumen de mercancías que se da en el tráfico comercial internacional, sino porque además, puede ser aplicado a un contrato 
tuvo mejor idea que dotarle de una normativa uniforme reguladora, sobre el plano meta-nacional ${ }^{4}$, de su correspondiente derecho sustancial.

La Convención de Viena (en adelante CV), para muchos el más brillante texto de los que conforman la denominada nueva Lex mercatoria ${ }^{5}$, o Derecho Uniforme del Comercio Internacional ${ }^{6}$, es la regla jurídica que gobierna actualmente las dos terceras partes del conjunto del comercio internacional de mercancías y parte del derecho

de compraventa internacional celebrado entre dos partes cuyas sedes negociales no se encuentren ubicados en alguno de los Estados contratantes. Cfr. Enrich - Malet, «La convención de las Naciones Unidas sobre los contratos de compraventa internacional de mercaderías», en Revista jurídica de Cataluña, Barcelona, 1991, N² 2, p. 443.

4 Cfr. Luzzato, «Vendita» (diritto internazionale privato), en Enciclopedia del diritto, Milano, 1993, vol. XLVI, p. 502; Ferrari, «El ámbito de aplicación del convenio de Viena sobre compraventa internacional", en Revista de derecho mercantil, Madrid, 1996, N$^{\circ} 221$, p. 841.

5 Esta Lex mercatoria ha surgido con la finalidad de superar aquella situación definida como anarquía con base en las relaciones internacionales; esto es, dirigida a superar la citada nacionalidad del derecho que se revela, precisamente, como un obstáculo para las relaciones económicas, siempre más intensas entre ciudadanos de Estados diferentes; un obstáculo, sobre todo, para las empresas que actúan en mercados internacionales y que adquieren materias primas o colocan mercancías en Estados diferentes, que cuentan cada uno con una legislación distinta. Cfr. Galgano, "Il diritto uniforme: la vendita internazionale", en Galgano (dir.), Atlante di diritto privato comparato, Bologna, 1992, p. 211 y ss; Id., Lex mercatoria, Bologna, 1993, p. 8 y ss.; Leyva Saavedra, La convención de Viena, op. cit., p. 166.

6 Bajo esta denominación, también bajo la de Derecho mercantil internacional o Derecho del comercio internacional o Lex mercatoria y alguna otra más, se incluyen normas que reúnen una serie mínima y elemental de características comunes. Estos rasgos compartidos deben de considerarse como el mínimo común denominador de la categoría que se pretende conceptuar. Los rasgos comunes definitorios de todas las normas que integran el Derecho uniforme son, de modo indiscutible, la internacionalidad, la uniformidad y el contenido obligacional privado de estas normas. Es discutible, por el contrario, que la autonomía de las normas, en lo que hace a su sistema de producción y de aplicación, constituya un rasgo esencial del actual Derecho uniforme del comercio internacional. No existe, por último, un elemento categorizador común a las normas analizadas derivado ni de la forma externa de las mismas ni, tampoco, de la procedencia de ellas, explica el profesor Illescas, «El derecho uniforme del comercio internacional y su sistemática», en Revista de derecho mercantil, Madrid, 1993, No 207, p. 39 y ss. 
interno de cincuentisiete Estados ${ }^{7}$, incluido el nuestro, que ha adherido a ella el 22 de febrero de 1999, mediante el Decreto Supremo No 011-99-RE, y ha depositado el instrumento de adhesión un mes después, el 23 de marzo, lo que significa que desde el primero de abril del presente año forma parte de nuestro derecho nacional, a tenor del Art. 99.2 de la propia Convención ${ }^{8}$.

Las razones del considerable éxito de la $\mathrm{CV}$ son múltiples. En relación a sus predecesoras, se presenta como un texto con mejoras evidentes y sustanciales a la que no alcanzan las acérrimas críticas que sufrieron los textos de La Haya de 1964. La Convención es un instrumento jurídico que ha sabido conciliar la diversidad de puntos de vista en juego; ha logrado un punto de encuentro entre los diferentes intereses económicos que enfrentan a los operadores comerciales, esto es, a los compradores y vendedores; ha puesto, igualmente, de acuerdo a países con estructuras políticas a primera vista irreconciliables; por último, ha podido conjugar, no sin pocas dificultades, las barreras jurídicas presentes en toda elaboración de textos para los que se pretende una aplicación universal ${ }^{9}$.

7 Los países que actualmente han incorporado la Convención a su Derecho interno son: Alemania, Argentina, Australia, Austria, Bélgica, Bielorrusia, BosniaHerzegovina, Bulgaria, Burundi, Canadá, Chile, China, Cuba, Dinamarca, Ecuador, Egipto, Eslovenia, España, Estados Unidos de América, Estonia, Federación de Rusia, Finlandia, Francia, Georgia, Grecia, Guinea, Hungría, Iraq, Italia, Kyrgyzstan, Letonia, Lesotho, Lituania, Luxemburgo, Mauritania, México, Moldavia, Mongolia, Noruega, Nueva Zelanda, Países Bajos, Perú, Polonia, República Árabe Siria, República de Croacia, República Checa, Eslovakia, Rumania, Singapur, Suecia, Suiza, Ucrania, Uganda, Uruguay, Uzbekistan, Yugoslavia y Zambia. Por su parte Ghana y Venezuela la han firmado pero todavía no se han decidido a incorporarla como parte de su Derecho interno. La lista de los países que la han incorporado a su derecho interno puede consultarse en: http://www.un.or.at/uncitral/status

8 Dispone esta norma que: «cuando un Estado ratifique, acepte o apruebe la presente Convención, o se adhiera a ella, después de haber sido depositado el décimo instrumento de ratificación, aceptación, aprobación o adhesión, la Convención, salvo la parte excluida, entrará en vigor respecto de ese Estado, sin perjuicio de lo dispuesto en el párrafo 6) de este artículo, el primer día del mes siguiente a la expiración de un plazo de doce meses contados desde la fecha en que se haya depositado su instrumento de ratificación, aceptación, aprobación o adhesión".

9 Cfr. Perales Viscasillas, La formación del contrato en la compraventa internacional de mercaderías, Valencia, 1996, p. 58 y ss. Entre los obstáculos más impor- 
La Convención de Viena es, pues, un bien hilvanado conjunto de normas sustantivas reguladoras del contrato de compraventa internacional; particularmente, reguladoras de la formación del contrato (Parte II), los derechos y obligaciones de compradores y vendedores, así como las acciones que pueden interponerse en los casos de incumplimiento de alguna de las partes de todas o parte de sus obligaciones contractuales o legales (Parte III: Capítulos II y III). Igualmente, la CV contiene importantes reglas relativas a su ámbito de aplicación (Parte I). Ella no dispone de reglas relativas al conflicto de leyes, esto es, reglas diseñadas para discernir qué norma resultará aplicable cuando existen varias legislaciones nacionales implicadas. Aquí, precisamente, radica la importancia de la $\mathrm{CV}$, ya que el abogado o empresario americano, argentino, español, chino o peruano tienen un lenguaje común para negociar: el representado por el conjunto de disposiciones de la Convención de Viena sobre compraventa internacional de mercaderías, evitando, en efecto, echar mano a las normas de derecho internacional privado de las leyes nacionales, que tanto complican este tipo de relaciones comerciales.

Como podemos observar, hay muchas aristas estudiables de la CV; una de ellas es la que atrae nuestra atención en esta oportunidad: la formación del contrato de compraventa internacional en la citada Convención. Esta parte, se ha dicho, es la más lograda y, por ende, la más importante que contiene el texto uniforme; de allí que su estudio resulte necesario para un mejor entendimiento y, al mismo tiempo, obligatorio para una mejor aplicación a las relaciones contractuales internacionales. No olvidemos que, desde el primero de abril tenemos

tantes que se tuvieron que superar a la hora de conseguir la unificación normativa del contrato de compraventa internacional fue el del enfrentamiento técnico-legal entre los países del área del common law y los del civil law, y ello debido a que "son dos tradiciones, dos culturas, que difieren en sus principios, en sus instituciones, en sus reglas e incluso en sus esquemas lógicos del razonar jurídico, hasta el punto que la unificación choca inevitablemente con las barreras de esas diferencias. Y la solución no puede venir por la vía del legal imperialism ni del legal transplant, por la imposición o el injerto de un sistema sobre otro, sino por el diálogo paciente, el espíritu de compromiso, la transacción generosa y las fórmulas de equilibrio", subraya Olivencia, "La Convención de las naciones unidas sobre los contratos de compraventa internacional de mercaderías: antecedentes históricos y estado actual", en Revista de Derecho mercantil, Madrid, 1991, $\mathrm{N}^{\circ} 201$, p. 394. 
una doble legislación para los contratos de compraventa: la del Código civil, para las compraventas nacionales, y la de la Convención de Viena, para las compraventas internacionales ${ }^{10}$.

\section{Apuntes históricos de la Convención de Viena}

La idea de dar vida a una reglamentación uniforme de la compraventa internacional se gestó a finales de la década del veinte, particularmente en 1929, año en el cual el Unidroit ${ }^{11}$, a propuesta del jurista alemán Ernest Rebel, decide emprender los trabajos preparatorios y confiar a un Grupo de trabajo, compuesto por los más renombrados comparatistas de la época, la preparación de un primer proyecto de ley uniforme sobre la materia, el que fue presentado en 1935. Este trabajo preliminar fue enviado a la Sociedad de Naciones y sometido por ésta a la consideración de los Estados miembros. Un texto revisado se publicó en $1939^{12}$.

Los trabajos se interrumpieron a causa de la segunda guerra mundial, pero se volvieron a emprender en 1951 con una conferencia en La Haya, con motivo de la cual se presentó un nuevo proyecto de ley uniforme. A este proyecto siguieron otros, siendo el último el que fue objeto de la Conferencia diplomática de La Haya, desarrollada del 1 al 25 de abril de 1964. En esta Conferencia, convocada por el gobierno

10 Cfr. Leyva Saavedra, «La convención de Viena», op. cit., p. 167.

11 El Instituto Internacional para la Unificación del Derecho Privado - International Institute for the Unification of Private Law, conocido como Unidroit o Instituto de Roma, por el lugar de su sede, fue fundado en setiembre de 1926 como un órgano auxiliar de la Sociedad de las Naciones. Después de la disolución de ésta, fue reconstituido en 1940, en virtud de un acuerdo multilateral. Cfr. Leyva Saavedra, "Contratos de empresa", op. cit., p. 134.

12 Cfr. Bonell, «Introduction to the convention», en Bianca - Bonell (coord.), Commentary on the international sales law, Milano, 1987, p. 3 y ss; Id., "La convenzione di vienna sulla vendita internazionale: origini, scelte e principi fondamentali", en Rivista trimestrale di diritto e procedura civile, Milano, 1990, No 3, p. 715 y ss; Ferrari, L'ambito di applicazione della convenzione, cit., p. 899 y ss; Adame Goddard, El contrato de compraventa internacional, México, 1994, p. 10 y ss.; Leyva Saavedra, La convención de Viena, op. cit., p. 167; Sierralta, La compraventa internacional y el derecho peruano, Lima, 1997, p. 8 y ss. 
Holandés, se aprobaron dos convenciones: la "Ley uniforme sobre la venta internacional de mercaderías» (LUVI, en inglés ULIS) y la «Ley uniforme sobre la formación de los contratos de venta internacional de bienes inmuebles corporales" (LUFC, en inglés ULFC). Estas convenciones, firmadas el $1^{\circ}$ de julio de 1964 , entraron en vigencia el mismo año: la primera, el 18 de agosto de 1972, al adherirse a ella Bélgica, Gambia, Holanda, Israel, Italia, el Reino Unido de Gran Bretaña e Irlanda del Norte, la República Federal de Alemania y San Marino; la segunda, el 23 de agosto de 1972, cuando la ratificaron los mismos países, con excepción de Israel ${ }^{13}$. Esta bipartición de la materia, que dividía la regulación de la formación y del contenido del contrato, respondía al deseo de lograr la máxima aceptación de estos instrumentos por los estados y, a la vez, respondía al temor de que la resistencia a adoptar las normas sobre formación del contrato determinase el rechazo, en bloque, de todo la normativa uniforme. La técnica de la doble Convención dejaba en libertad a los Estados para aceptar ambas o, simplemente, una de ellas.

Pese a esta ingeniosa metodología, la aceptación de las citadas convenciones fue escasa. En los debates de la Conferencia se puso ya de manifiesto la dificultad de la tarea. Las posiciones de las delegaciones de Estados pertenecientes a los sistemas del civil law y del common law se radicalizaron, y solo una actitud de respeto a los esfuerzos unificadores de Unidroit, invocada por la delegación sueca, condujo a soluciones de compromiso. Pero la debilidad de éstas se reflejó en la famosa «reserva quinta», introducida al final de la Conferencia por la delegación del Reino Unido, que permitía que cada Estado, en el momento de su ratificación o adhesión, declarase que no aplicaría la Ley uniforme más que en los casos que las partes la hubieran elegido como aplicable. Este amplio reconocimiento a la autonomía de la voluntad convertía a la Ley uniforme en un texto de aplicación convencional y, en efecto, desnaturalizaba su propio carácter ${ }^{14}$.

13 Las dos convenciones siguen en vigencia entre los países que no las han denunciado. Según el artículo $99^{\circ}$, párrafos 3 al 6 , de la Convención de Viena, todo Estado que ratifique, acepte o apruebe esta Convención, o adhiera a ella, y que sea parte en una o en ambas convenciones de La Haya de 1964, deberá denunciarlas, mediante notificación al gobierno de los Países Bajos.

14 Cfr. Olivencia, "La convención de las naciones unidas", op. cit., p. 386. 
A esa debilidad intrínseca de las leyes uniformes de La Haya se unieron otras causas que abonaron su escaso éxito, a saber: la escasez de Estados representados en la Conferencia, la homogeneidad dominante de los países occidentales, de economía de mercado, desarrollados e industrializados, la oposición de los países de economía colectivista y la irrupción en la esfera internacional de los países del "tercer mundo", que abrieron frentes contra la aceptación de un derecho uniforme en cuya elaboración no habían participado, tildándolo de protector de intereses contrarios a los de sus propios países. No obstante estos obstáculos, ambas Convenciones, con el mínimo de instrumentos de ratificación y adhesión, como hemos apuntado, entraron en vigencia en 1972.

Este poco éxito de las leyes ${ }^{15}$, motivó que en 1968 Uncitral $^{16}$, aun antes que entraran en vigor, iniciara la revisión sustancial de ambas. Esta inicial revisión se tradujo en una necesaria regulación elaborada ex novo. Se presentaron varios proyectos, pero fue el de 1978 el que resultó aprobado por la Comisión y presentado para su examen en la Conferencia diplomática, convocada por la Asamblea General de las Naciones Unidas, por Resolución de 16 de diciembre de 1978, y desarrollada en el Palacio Imperial de Hofburg, en Viena, del 10 al 11 de abril de 1980, que concluyó con la aprobación unánime de los representantes de sesentidós países presentes en la Conferencia, de la llamada Convención de las Naciones Unidas sobre los contratos de compraventa internacional de mercaderías (United Nations Conventions on Contracts for the International Sale of Goods - Convention des Nations Unies sur les Contrats de Vente International de Marchandise). En esta Conferencia se aprobó, igualmente, el Protocolo de enmiendas a la Convención sobre

15 Las expectativas despertadas por estas leyes no se cumplieron, por lo que su aplicación fue muy limitada. Cfr. Bonell, "La convenzione di Vienna», op. cit., p. 716; Ferrari, Lambito di pplicazione della convenzione, op. cit., p. 843; Leyva Saavedra, "La convención de Viena», op. cit., p. 168.

16 Las Naciones Unidas, mediante Resolución N²205 (XXI) de la Asamblea General del 17 de diciembre de 1966, con el objeto de promover la armonización y la unificación progresiva de derecho mercantil internacional, constituyó la Comisión de las Naciones Unidas para el Derecho Mercantil Internacional - The United Nations Commission on International Trade Law, conocido como Cnudmi o Uncitral, según el anagrama inglés. Los trabajos de la Comisión comenzaron en 1968 en New York. Cfr. Leyva Saavedra, "Contratos de empresa", op. cit., p. 134. 
la Prescripción en materia de Compraventa Internacional de Mercaderías.

La Convención, no obstante su unánime aprobación, tuvo que esperar cerca de ocho años para su entrada en vigencia. El Art. $99^{\circ} \mathrm{CV}$, como hemos visto, dispone que ésta entrará en vigor el primer día del mes siguiente a la expiración del plazo de doce meses contados desde la fecha de depósito del décimo instrumento de ratificación, aceptación, aprobación o adhesión. Tras Leshoto, Francia, Siria, Egipto, Hungría, Argentina, Yugoslavia y Zambia, que fueron los ocho primeros depositantes, lo hicieron Italia, China y Estados Unidos, el mismo día (11 de diciembre de 1986), lo que permitió que la CV entrará en vigor el $1^{\circ}$ de enero de 1988. En la actualidad, como hemos dicho, ha sido incorporada al derecho interno de cincuentisiete países, siendo, además, numerosos los países que han anunciado su intención de seguir este ejemplo, lo que nos hace augurar que en un futuro cercano la Convención será de aplicación en todo el mundo.

\section{Formación del contrato de compraventa internacional}

La formación del contrato es una de las partes más importantes de la estructura contractual; es la columna vertebral de todo este sistema. Los redactores de la LUVI y de la CV concientes de ello, consideraron necesario dotarla de una regulación uniforme por entender que, en este lugar, podían producirse notables discrepancias entre las partes contratantes $\mathrm{y}$, probablemente, lo más importante, sensibles diferencias entre los Derechos nacionales ${ }^{17}$. Surgió de este modo, la LUFC y, sobre la base de ésta, se elaboró la regulación de la formación del contrato que contiene la CV.

La Convención de Viena, en una forma que contrasta con muchas leyes nacionales, regula de manera muy completa la formación del contrato de compraventa de mercaderías en la parte II, compuesta por once artículos: cuatro que regulan la oferta (arts. $14^{\circ}$ al $17^{\circ}$ ), seis que se ocupan de la aceptación (arts. $18^{\circ}$ al $23^{\circ}$ ) y uno que norma la efectividad de las declaraciones de voluntad (Art. $24^{\circ}$ ). Toda esta normati-

17 Cfr. Díez-Picazo, "La formación del contrato», en Anuario de Derecho civil, Madrid, 1995, t. XLVIII, fasc. I, p. 5. 
va, que se alza sobre el esquema clásico de contratar, está diseñada para acomodar sus declaraciones de voluntad -oferta, revocación, aceptación, retirada y demás comunicaciones - a los medios de comunicación que utilicen las partes contratantes. Está pensada para dar cobijo tanto a las declaraciones orales como escritas, sin que se distingan los contratos entre presentes y entre ausentes. Ciertamente, el texto uniforme se preocupa fundamentalmente por las declaraciones que se realizan por escrito, ya que en las orales el iter formativo es en la práctica simultáneo e implican necesariamente el conocimiento por los interesados del contenido de la declaración de voluntad; hecho de por sí excluyente de los inconvenientes graves que pueden presentarse en el proceso formativo de un contrato en el que la separación temporal entre las declaraciones de voluntad (oferta y aceptación) es dilatado debido al medio de comunicación que se utilice.

Esta preocupación de la Convención por el tipo de contratación comentada se detecta a simple vista de un examen de las disposiciones de la parte II. El Art. 18.2 CV, en su último inciso, establece que la aceptación de las ofertas verbales tendrá que ser inmediata, y el Art. $24^{\circ} \mathrm{CV}$ acoge la teoría de la cognición para fijar el momento en que una declaración oral «llega» al destinatario, mientras que para las declaraciones realizadas por escrito formula la teoría de la recepción. Es, además, la propia CV la que en su articulado diferencia entre las comunicaciones verbales y las escritas, reconociendo los siguientes medios de comunicación para el intercambio de la oferta y la aceptación, así como para las demás notificaciones que se dirijan las partes contratantes: la comunicación verbal y las realizadas por escrito: carta, telegrama, télex, fax, e-mail (electronic mail) y EDI (Electronic Data Interchange) ${ }^{18}$.

Ahora bien, como quiera que las citadas disposiciones regulan la formación de los contratos de compraventa internacional a través del esquema de concurrencia de dos declaraciones de voluntad (oferta y aceptación), los comentaristas se han planteado la siguiente interrogante: ¡se excluye las demás posibles modalidades de formación de los contratos que no se atengan a ese esquema? Esto ocurrirá, en particular, cuando el contrato haya sido objeto de una larga negociación y de diferentes proyectos debatidos, de manera que no sea posible definir ninguno de ellos como oferta. Tampoco responden al esquema lineal

18 Cfr. Perales Viscasillas, La formación del contrato, op. cit., p. 158 y ss. 
de concurrencia de oferta y aceptación los contratos que pueden haber sido formados a través de los esquemas de subasta y de concurso, los de formación progresiva, los articulados a través de una fase precontractual y otros muchos. No parece que estas posibilidades hayan quedado excluidas y, en el supuesto que se produzcan, deberán ser reguladas atendiendo a las líneas de inspiración de la CV y, subsidiariamente, por las reglas del derecho nacional aplicable a tales actos ${ }^{19}$.

\section{Oferta y propuesta contractual}

La Convención, en su Art. $14^{\circ}$, señala que «la propuesta de celebrar un contrato, dirigida a una o varias personas determinadas, constituirá oferta si es suficientemente precisa e indica la intención del oferente de quedar obligado en caso de aceptación". Esta norma, se ha dicho, se inspira en una concepción que distingue la propuesta contractual de la oferta propiamente dicha. La primera constituye el género y, dentro de ella, como una especie particular, se sitúa la oferta, que es una propuesta que reúne unos determinados y estrictos requisitos. La propuesta contractual es una declaración que manifiesta la intención de llegar en lo sucesivo a establecer un contrato que queda inicialmente diseñado en alguno de sus elementos. Es un proyecto cuya finalidad se limita a abrir el proceso que conducirá, eventualmente, a la formación del contrato.

Por la forma como se presenta redactada la citada norma, el género "propuesta contractual» parece dividirse en dos especies distintas: por una parte, se encuentran las genuinas ofertas y, por otra, las llamadas invitaciones a ofrecer, que pueden ser interrogaciones sobre posibles intenciones, solicitudes de información o, en sentido estricto, invitaciones ${ }^{20}$. Veamos cada una de ellas.

19 Cfr. Díez-Picazo, "Comentario al artículo $14^{\circ}$ », en Díez-Picazo (dir.), Compraventa internacional de mercaderías. Comentario de la convención de Viena, Madrid, 1998, p. 165.

20 Cfr. Díez-Picazo, La formación del contrato, op. cit., p. 6; Id., "Comentario al artículo $14^{\circ}$ ", op. cit., p. 165. 


\section{La oferta}

Coincidiendo con el sistema propuesto por la CV, podemos definir la oferta como aquella declaración de voluntad recepticia que, siendo suficientemente precisa, se encamina a perfeccionar un contrato con la sola aceptación del destinatario de la misma. Habiendo aceptación, en efecto, el contrato quedará constituido, sin necesidad de emitir nuevas o distintas declaraciones de voluntad. Esto es lo que quiere destacar el Art. 14.1 CV al hablar de la intención del oferente de quedar obligado en caso de aceptación. Aquí, quedar obligado significa quedar vinculado contractualmente.

\subsection{Elementos de la oferta}

De la lectura del Art. $14^{\circ} \mathrm{CV}$ se deduce que se necesita la concurrencia de dos elementos esenciales para que una declaración de voluntad pueda considerarse como una oferta, a saber: a) indicar la intención de oferente de quedar obligado en caso de aceptación; b) ser suficientemente precisa.

a) Intención del oferente. La voluntad del oferente de quedar obligado o vinculado con la sola aceptación es una intención caracterizable como una genuina voluntad negocial. El Art. 14.1 CV requiere, además, que esta voluntad o intención del oferente esté indicada en la propia oferta. Esto exige que en la declaración de la oferta se encuentre la intención de obligarse o que, dados los términos en que la oferta se produzca, deba entenderse objetivamente que en ella se encuentra implícita tal voluntad. La determinación de la existencia de esta voluntad o intención de quedar obligado y de su suficiente expresión en la propuesta, es una cuestión de interpretación ${ }^{21}$. Resultan aplicables en esta parte los arts. $7^{\circ}$ al $9^{\circ} \mathrm{CV}$, parti-

21 Cfr. Díez-Picazo, Fundamentos del derecho civil patrimonial, Madrid, 1996, vol. I, p. 284; Id., "Comentario al artículo 140", op. cit., p. 166. En materia de interpretación, recuerda este autor, se abren dos grandes líneas (la llamada interpretación subjetiva, vinculada a la voluntad real del declarante, y la interpretación objetiva, que busca más bien el sentido que razonablemente puedan encontrar los destinatarios de la declaración para proteger las expectativas y la confianza que ellos se 
cularmente la regla de la buena fe y la regla que señala que debe tenerse en cuenta el sentido dado por una persona razonable, de acuerdo con todas las circunstancias del caso y los usos y prácticas existentes entre las partes contratantes con anterioridad a la celebración del contrato.

Una oferta, cabe agregar, no necesita contener las palabras «oferta de contrato" para que vincule al oferente; lo único que es necesario es que se derive del contenido de la oferta el nacimiento de un contrato. No puede entenderse, entonces, que existe una oferta si se añade alguna cláusula del tipo "salvo aceptación de la casa", "sin compromiso" u otras análogas, pues aquí está ausente la voluntad de obligarse.

b) Precisión de la oferta. Para favorecer la celebración de los contratos, la CV ha sustituido el tradicional requisito del carácter completo de la declaración del oferente por el más matizado de la suficiente precisión. Así, dispone el Art. 14.1 CV que para que la oferta sea suficientemente precisa basta que indique las mercaderías y que, expresa o tácitamente, señale la cantidad y el precio o provea un medio para determinarlos.

La cantidad y el precio, por lo visto, pueden ser señalados de forma expresa (5.000 unidades a 10 dólares por unidad) o de forma implícita (por remisión a las negociaciones previas, a los usos ${ }^{22}$ o prácticas establecidas con anterioridad por los contratantes ${ }^{23}$ ). Además pueden ser

hayan suscitado), por lo que hay que determinar qué tipo de interpretación es la que debe predominar en esta materia. La Convención de Viena introduce al respecto normas de cuyo carácter objetivo no cabe dudar, como es la aplicación de los usos particulares existentes entre los declarantes y la regla de la buena fe, de una manera que parece objetivar el contrato (La formación del contrato, op. cit., p. 7).

22 Por ejemplo se ha señalado que la falta de indicación de una específica cantidad en una oferta de gas propano - sólo se señalaba una cantidad aproximada -, no es un obstáculo para la validez del contrato, ya que se trata de un uso en el sector del comercio en cuestión (gas propano): Oberster Gerichtshof, 6 febrero 1996 (Austria) (PACE) (UNILEX).

23 Buena prueba de ello es la acertada sentencia del Tribunal Municipal de Budapest de 24 de marzo de 1992 (Hungría) (PACE) (UNILEX). Se trata de la compraventa de determinadas mercancías realizada por teléfono entre un vendedor alemán y un comprador húngaro sin que se hubiesen mencionado los aspectos relativos a la can- 
determinados o determinables, por ejemplo por referencia al valor de bolsa de un determinado día, siempre que en la oferta queden fijadas las bases para su determinación o las ofertas que señalen "todas mis existencias", "todo lo que necesite ${ }^{24}$ o «una gran cantidad de $[\ldots] \|^{25}$, o estableciendo un tope máximo y otro mínimo ${ }^{26}$. Tanto el precio como la cantidad pueden determinarse por un tercero o, incluso, por una de las partes. En caso de que ninguna de ellas pueda determinarlo, parece que se podría aplicar el estándar de la razonabilidad para subsanar esa deficiencia ${ }^{27}$. En cuanto a la forma que debe revestir la oferta,

tidad, calidad y precio de las mismas. El tribunal, tras determinar que la ley aplicable es la Convención de Viena de 1980, concluye declarando la existencia implícita de esos elementos en la oferta contractual, habida cuenta de la obligatoriedad que para las partes representan las prácticas seguidas con anterioridad (arts. 9.1 y 14.1 CV).

24 Comentario de la Secretaría al actual artículo $144^{\circ}, \$ 12$. Esta forma de determinar la cantidad es típica en el derecho estadounidense, concretamente en los denominados output contracts y requirement contracts (sección 2-306 UCC).

25 Piel de chinchilla («eine grössere Menge Chinchilla Felle»): Oberster Gerichtshof, 10 noviembre 1994 (Austria) (PACE) (UNILEX).

26 Por ejemplo, una oferta que fija la cantidad entre 15.000 y 20.000 , estableciéndose su concreta determinación para un momento posterior: Tribunal de Comercio de Poitiers, 9 diciembre 1996 (Francia) (PACE) (UNILEX). O una oferta que fija un precio por pieza entre un límite mínimo de 35 marcos alemanes y un máximo de 65 en función del grado de calidad -media o superior- de la mercancía: Oberster Gerichtshof, 10 noviembre 1994 (Austria) (PACE) (UNILEX).

27 En contra: Tribunal de Arbitraje Comercial Internacional de la Cámara de Comercio e Industria de la Federación Rusa, 3 marzo 1995 (PACE) (UNILEX), juzgando un caso entre un comprador austríaco y un vendedor ucraniano declaró la no perfección del contrato. El tribunal indicó que la comunicación realizada por télex por el vendedor de Ucrania donde se indicaba la fecha de entrega, la naturaleza y la cantidad, no podía considerarse suficientemente precisa, puesto que omitía determinar el precio o un medio para su determinación. En el télex se señalaba que el precio debía ser acordado diez días antes del comienzo del nuevo año. En opinión del tribunal, ello no constituye una indicación suficientemente precisa acerca del precio (art. 14.1 CV), sino una mera expresión de asentimiento para determinar el precio de las mercancías en una fecha futura mediante acuerdo de las partes. El comprador austríaco que confirmó el contenido del télex también consintió en que el precio de las mercancías fuese acordado en un futuro por las partes. El tribunal también señaló que el Art. $55^{\circ} \mathrm{CV}$ no era aplicable ya que las partes implícitamente indicaron la necesidad de acordar el precio en un momento posterior. Por tanto, el tribunal concluyó señalando la no perfección del contrato. 
rige el principio de libertad de forma; según esto, la oferta podría estar contenida en una factura ${ }^{28}$.

\subsection{Contratos con precio abierto}

Distinta de la mención expresa o implícita en la oferta de contrato, es la cuestión que se plantea con los llamados contratos con precio abierto (open price contracts), es decir, de aquellos contratos que nada dicen acerca del precio. Los diversos ordenamientos jurídicos no coinciden acerca del tratamiento de esta cuestión. Así, mientras el ordenamiento español y el francés ${ }^{29}$, entre otros, no permiten la existencia de contrato sin precio; en los ordenamientos del common law, como el estadounidense y el inglés ${ }^{30}$, por ejemplo, se permite la existencia de contratos carentes del elemento precio. La cuestión se complica en la Convención, y fue además sumamente debatida durante los trabajos previos, porque el Art. $14^{\circ} \mathrm{CV}$ señala que en la oferta de contrato debe existir un precio, mientras que el Art. $55^{\circ} \mathrm{CV}$ establece una forma de subsanar la falta de ese elemento cuando el contrato ha sido válidamente perfeccionado; de manera precisa indica que se aplica el precio generalmente cobrado en el momento de la celebración del contrato por tales mercaderías, vendidas en circunstancias semejantes, en el tráfico mercantil de que se trate. Las posturas de la doctrina en torno a esta cuestión giran desde los que consideran que no es posible la existencia de un contrato sin precio $^{31}$, excepto en muy particulares cir-

28 Cámara Nacional en lo Comercial, sala E, 14 octubre 1993 (Argentina) (Carlos III); LG Aachen, 14 mayo 1993 (Alemania) (PACE) (UNILEX), ambos enjuiciando contratos en los que la oferta se contenía en una factura.

29 Código civil español, arts. $1449^{\circ}$ y $1450^{\circ}$; Code civil, arts. $1591^{\circ}$ y $1592^{\circ}$.

30 Derecho estadounidense (sección 2-305 UCC) y Derecho inglés (artículo $8^{\circ}$ Sale of Goods Act). Vid., También, Derecho alemán (pfo. 317 BGB); Derecho austriaco (pfo. 1054 ABGB); Derecho italiano (Art. 14740 CC), Derecho suizo (Art. 212.1 COS) y Derecho peruano (Art. $1547^{\circ} \mathrm{CC}$ ).

31 Cfr. Bydlinski, Das Allgemeine Vertragsrecht, en Doralt (ed.), Das UncitralKaufrecht im Vergleich zum Österreichischen Recht, Wien, 1985, p. 63; Tallon, The Buyer's obligations under the Convention on Contracts for the International Sale of Goods, en Galston - Smit, International Sales: The United Nations Convention on Contracts for the International Sale of Goods, New York, 1984, p. 7 y ss. 
cunstancias $^{32}$, hasta los que sostienen que sí y que el método de determinación del precio previsto en el Art. $55^{\circ} \mathrm{CV}$ vendría a suplir esa falta ${ }^{33}$, pasando por los que señalan que se trata de una cuestión de validez que ha de enjuiciarse conforme a las reglas del derecho nacional no uniforme que resulte aplicable ${ }^{34}$.

En principio, una interpretación correcta entre los artículos $14^{\circ} \mathrm{y}$ $55^{\circ} \mathrm{CV}$ pasa por la determinación de la expresión «cuando el contrato

32 En particular, cuando se trate de: a) países que han declarado inaplicable la parte II de la Convención mediante la reserva del Art. 92 $\mathrm{CV}$ (Noruega, Finlandia, Dinamarca y Suecia); b) partes involucradas en un contrato de compraventa que no han indicado el precio de la transacción (expresa o implícitamente) ni señalado un medio para su determinación; y c) que el derecho interno no uniforme que resulte de aplicación declare el contrato válidamente celebrado, por lo que se podrá aplicar el método de determinación del precio que el Art. $55^{\circ} \mathrm{CV}$ establece.

33 Vid. Honnold, Uniform Law for International Sale under the 1980 United Nations Convention, Deventer, 1991, p. 196 y ss.; Sono, Formation of International contracts under the Vienna Convention: A shift above the comparative Law, en Volken - Sarcevic (coord.), International Sale of Goods, New York, London, 1986, p. 120 y ss.; Fortier, Le prix dans la Convention de Vienne sur la vente internationale de marchandises: les articles 14 et 55, en Journal du droit international, 1990, $\mathrm{N}^{\circ} 2, \mathrm{p}$. 389; Adame Goddard, El contrato, op. cit., p. 94 y ss.; Díez-Picazo, La formación del contrato, op. cit, p. 10; Murray, An Essay on the Formation of Contracts and Related Matters Under the United Nations Convention on Contracts for the International Sale of Goods, en The journal of law and commerce, 1988, vol. 8, $\mathrm{N}^{\circ} 1$, p.14 y ss.; Garro, Reconciliation of Legal Traditions in the UN Convention on Contracts for the International Sale of Goods, en The international lawyer, 1989, vol. 23, N², p.443 y ss.; Muguillo, Contrato de compraventa. Contratos «a precio abierto" y "a fijar precio" en nuestro Derecho y en la CCVIM de Viena 1980, en Estudios de derecho comercial, Buenos Aires, 1991, N 7, p. 95 y ss.; Adami, Les contrats "open price» dans la Convention des Nations Unies sur les contrats de vente internationale de marchandises, en Droit des affaires internationales, Paris, $1989, \mathrm{~N}^{\circ} 2$, p.110 y ss.

El ICC Model International Sale Contract (Manufactured Goods Intended for Resale), final Draft 17 March 1997 (ICC, Doc. N 470-9/16) evita cualquier discusión al entender en las condiciones generales que si no se ha fijado precio, la lista de precios del vendedor en vigor en la época de perfección del contrato determinará ese elemento. En su defecto, el precio generalmente cobrado por tales mercancías en el momento de la celebración del contrato será aplicable.

34 Vid., Heuzé, La vente internationale de merchandises. Droit uniforme, París, 1992, p. 60; y Rehbinder, Vertragsschluss nach UN-Kaufrecht im Vergleich zu EAG und $B G B$, en Schlechtriem (coord.), Einhetliches Kaufrecht und Nationales Obligationenrecht, Baden-Baden, 1987, p. 158. 
haya sido válidamente celebrado" que son las palabras introductorias del artículo $55^{\circ} \mathrm{CV}$. Nos parece que el contrato puede ser válidamente celebrado sin que éste incluya el precio cuando la voluntad de las partes (Art. $6^{\circ} \mathrm{CV}$ ) expresa o implícitamente expresada lleva a esa conclusión, lo que, desde luego, sucederá en todas aquellas circunstancias en que exista ejecución contractual ${ }^{35}$. Se reconoce, en consecuencia, la posible exclusión implícita del elemento precio señalado en el Art. $14^{\circ}$ CV; para ello habrá de asistirse de la ayuda interpretativa del Art. $8^{\circ}$ $\mathrm{CV}^{36}$. Más problemáticas son las situaciones en las que no existe ejecución del contrato. La jurisprudencia que se ha enfrentado con estos supuestos ha declarado la imposibilidad de entender el contrato perfeccionado. Por ejemplo, no puede entenderse el contrato perfeccionado

35 Una sociedad suiza envió el 3 de diciembre de 1991 por fax (no firmado) una orden de tres piezas para ordenadores (PMC-Schneideplotter), junto con una indicación de diferentes direcciones para su envío, así como con la expresión Liefertermin sofort (envío inmediato). La vendedora alemana envió a los pocos días los componentes. Como el precio no se pagó, el vendedor alemán acudió a los tribunales. El comprador alegó en relación con la perfección del contrato, en primer lugar, que el fax no era una oferta válida y que, por consiguiente, tampoco existía un contrato válido y, que no se cumplían los requisitos del Art. $14^{\circ} \mathrm{CV}$, ya que el fax no indicaba el precio. El tribunal sin referirse al Art. $55^{\circ} \mathrm{CV}$, indicó simplemente que la oferta era válida. En este sentido se basa en que la intención del oferente se deduce tanto del término "orden o pedido" (Bestellung), así como de la expresión "envío inmediato", y que el contrato se entiende perfeccionado, ya que el envío de las mercaderías se produjo al poco tiempo de haberse recibido la oferta. Se trata claramente de un caso en que por virtud de la oferta, el oferente autoriza al destinatario a aceptar mediante la ejecución de un acto, como es el envío de las mercancías, sin necesidad de comunicar dicha aceptación al oferente (Art.18.3 CV, que, sin embargo, no es nombrado por el tribunal). Vid. Handelsgericht St. Gallen, 5 diciembre 1995 (Suiza) (PACE) (UNILEX); Bezirksgericht St. Gallen, 3 julio 1997 (Suiza) que en una compraventa entre un holandés (vendedor) y un suizo (comprador) entendió fijado el precio por aplicación del Art. $55^{\circ}$, aunque las partes no lo habían pactado, si bien el contrato sí se había ejecutado.

36 En el caso de envío de catálogos, los usos del comercio internacional - ampliamente conocidos y regularmente observados - pueden servir de ayuda para deducir si el precio incluido en el catálogo debe ser considerado como el precio real del producto indicado en el mismo (Art. 9.2 CV). En caso afirmativo, se podría interpretar que el comprador ha hecho una indicación tácita "suficientemente precisa" del precio. Así, Garro - Zuppi, Compraventa internacional de mercaderias, Buenos Aires, 1990, p. 106. 
cuando la oferta no fija el precio de uno de los motores de avión ofertados ${ }^{37}$; así tampoco cuando la oferta (contraoferta, Art. 19.1) no menciona el precio de los productos ni prevé una forma para su determinación $n^{38}$.

\subsection{Retirada y revocación de la oferta}

En la Convención se utilizan dos términos que a simple vista parecerían tener el mismo significado y los mismos efectos; sin embargo, esto no es verdad, ya que la $\mathrm{CV}$ acuña una terminología suficiente para distinguir ambos conceptos. Así, en el texto inglés la idea de retirada se expresa utilizando el término withdrawal, mientras que para la revocación se utiliza el término latino revocation. No cabe duda que se trata

37 Nos referimos al primer caso que examina -si bien insuficientemente- la problemática de los contratos con precio abierto en el ámbito de la Convención: Tribunal Supremo de la República Húngara, 25 septiembre 1992 (Hungría) (PACE) (UNILEX). No obstante la sentencia de instancia declaró el contrato perfeccionado, pero sin mención de la problemática representada por los contratos con precio abierto: Tribunal Municipal de Budapest, 10 enero 1992 (Hungría) (PACE) (UNILEX). Traducción al inglés por el abogado defensor de la Compañía Pratt and Whitney Dr.Lászlo Szlávnits. Al respecto: "Interpretetive Decisions Applying CISG», en The journal of law and commerce, 1993, vol. 13, p. 31 y ss. Vid., también, los comentarios a las mismas realizados por Amato, Recent Developments: CISG. U.N. Convention on Contracts for the International Sale of Goods- The Open Price Term and Uniform Application: An Early Interpretation by the Hungarian Courts, en The journal of law and commerce, 1993, vol. 13, p. 1 y ss.; Vida, Unwirksamkeit der Offerte wegen Unbestimmtheit nach UN-Kaufrecht, en IPrax, 1995, núm. 4, p. 261 y ss.; Lecossois, La détermination du prix dans la Convention de Vienne, le U.C.C. et le droit français: critique de la première décision relative aux articles 14 et 55 de la Convention de Vienne, en Mc Gill Law Journal/Revue de Droit de Mc Gill, 1996, vol. 41, p. 513 y ss.; Perales Viscasillas, La formación del contrato, op. cit., p. 362 y ss.

$\mathrm{Al}$ respecto, es útil revisar el caso resuelto por el Handelsgericht des Kantons Aargau, 26 septiembre 1997 (Suiza), donde no existió ejecución del contrato, pero el Tribunal declaró la validez del contrato pese al silencio de la oferta en torno al precio. La oferta de compra identificaba las mercancías -juegos de cuchillería-, la cantidad - un número determinado de juegos - y la fecha de entrega, lo que constituye, en opinión del Tribunal, una oferta suficientemente precisa de conformidad con el Art. 14.1 CV. En el caso en cuestión el vendedor procedió a la entrega, pero el comprador la rehusó alegando que el contrato no había sido válidamente celebrado.

38 LG Frankfurt am Main, 4 marzo 1994 (Alemania) (PACE) (UNILEX). 
de expresiones con significado diferente, que deben ser mantenidas como distintas, toda vez que esta distinción es clave para la interpretación de los arts. $15^{\circ}$ y $16^{\circ} \mathrm{CV}$.

La retirada es una declaración de voluntad del oferente que indica su voluntad de dejar sin efecto una anterior declaración emitida, cuando ésta todavía no ha alcanzado efectividad. Se permite la retirada en el período de tiempo o en la fase de formación que media entre la emisión de la oferta y la recepción o llegada de la misma al destinatario. En cambio, revocación es la declaración de voluntad de cancelación de la oferta y de sus efectos, en el período que media entre la recepción de la oferta y la perfección del contrato. La consecuencia práctica más importante de la distinción es permitir la retirada de las ofertas aun cuando éstas tengan el carácter de irrevocables (Art. 15.1 CV). La retirada de la oferta es, lógicamente, libre y está sometida únicamente al requisito de temporalidad: que llegue antes o al mismo tiempo que la oferta. Como es una declaración que no ha alcanzado efectividad alguna, el destinatario de la retirada no puede alegar ningún justo motivo para impedir dicha retirada, puesto que ningún tipo de confianza, ni de interés atendible podrá haberse creado en él ${ }^{39}$.

El plazo para retirar la oferta, como hemos visto, concluye en el momento de la llegada de la oferta al destinatario. Si la retirada se ha llevado a cabo antes de la llegada de la oferta, utilizando un medio de comunicación más rápido y el destinatario la recibe antes, nada podrá reclamar ni alegar. Esto, naturalmente, ocurre también cuando se produce una coincidencia temporal en la llegada de ambas comunicaciones. Pero, si la declaración de retirada llega fuera de este plazo, nada impide que pueda o deba valer como revocación.

La revocación, como hemos adelantado, es una declaración de voluntad del oferente que tiene como propósito fundamental privar de eficacia a la oferta. A diferencia de la retirada, que se produce en la primera fase de formación del contrato, esto es, antes que llegue la oferta; la revocación se produce en la segunda, es decir, en el tiempo que media entre la llegada de la oferta al destinatario y el momento de la aceptación o rechazo de la misma. Reza el Art. 16.1 CV, «La oferta

39 Cfr. Díez-Picazo, La formación del contrato, cit., p. 14; Id., Comentario al artículo 15, cit., p. 172. 
podrá ser revocada hasta que se perfeccione el contrato si la revocación llega al destinatario antes que éste haya enviado la aceptación».

La regla general nos dice que toda oferta puede ser revocada porque no existe ningún tipo de vinculación contractual del oferente, pues éste simplemente ha emitido una comunicación dirigida a motivar la formación de un contrato, no a cerrar el circuito contractual. El solo hecho de haber llegado la oferta al destinatario no crea en éste una situación jurídica de confianza que merezca alguna dosis de protección jurídica.

Ahora bien, si la regla es que el oferente tiene la facultad o poder de revocar porque no ha quedado todavía vinculado contractualmente, el efecto lógico es que la revocación quede impedida una vez que se ha dado la aceptación del destinatario y, por consiguiente, formado el contrato $^{40}$. Esta regla se encuentra expresamente recogida en el Art. 16.1 CV, que establece un límite temporal condicionado. De acuerdo con la primera parte de la norma, el límite temporal de la facultad de revocación es el momento de la perfección del contrato; esto supone, en aplicación de las normas generales de la Convención, que el momento en que la aceptación surte efectos y el momento de efectividad de la misma es la recepción de ésta por el oferente (Art. $24^{\circ} \mathrm{CV}$ ). Sin embargo, en la parte de límites a la facultad revocatoria, la Convención modifica la regla general de la recepción y se inclina por la teoría de la emisión. Esta solución, se dice, ha sido adoptada para no otorgar al oferente una ventaja que pueda considerarse excesivamente prolongada ${ }^{41}$.

40 La regla establece que la revocación es posible hasta el momento en que se perfeccione el contrato siempre que la revocación llegue al destinatario antes de que éste envíe la aceptación. Si bien en un plano teórico, puede hacerse la distinción (revocación hasta la perfección cuando se utilizan medios de comunicación instantáneos; y revocación hasta el envío de la aceptación cuando se utilizan el correo y el telégrafo), en un plano práctico resulta que la revocación puede hacerse hasta antes del envío de la aceptación, ya que la perfección del contrato cuando se utilizan medios de comunicación instantáneos se produce casi simultáneamente al envío.

41 Cfr. Díez-Picazo, La formación del contrato, op. cit., p. 15; Id., Comentario al artículo $15^{\circ}$, op. cit., p. 175. Esta norma se justifica por dar seguridad al aceptante que, de otro modo, no tendría certeza de que no será revocada la oferta que ha aceptado, sino hasta que la aceptación llegara al oferente; en cambio, ella hace que el oferente tenga inseguridad acerca de si puede revocar una oferta cuya aceptación no ha recibido, escribe Adame Goddard, El contrato, op. cit., p. 99. 
Cabe agregar que en la discusión entre oferta revocable y oferta irrevocable, planteada en la legislación y jurisprudencia comparadas, la Convención se ha inclinado, en línea de principio, por la revocabilidad de la oferta, modificando el sentido del derecho alemán, así como de la jurisprudencia belga y holandesa, que parece inclinada a considerar, como regla general, la irrevocabilidad de la oferta, a menos que exista expresa reserva de la facultad revocatoria.

Por último, debemos señalar que, además de la facultad de retirar y de revocar la oferta que se concede al oferente, el destinatario puede rechazar el contenido de la oferta (Art. $17^{\circ} \mathrm{CV}$ ), lo que significa extinción de la oferta. El rechazo es efectivo cuando llega al oferente, lo que, de nuevo, se enjuicia conforme a la regla general establecida en el artículo $24^{\circ} \mathrm{CV}$. El rechazo de la oferta impide que vuelva a revivir, por ejemplo, porque el destinatario de la oferta se arrepienta de su rechazo y pretenda volver a aceptar la oferta.

\subsection{Irrevocabilidad de la oferta}

Tras establecer la Convención la regla general de la revocación de la oferta hasta la perfección del contrato o el envío de la aceptación, se encarga de indicar expresamente, en el Art. 16.2 CV, las dos excepciones a la regla. Eörsi, por su parte, estima que se trata de una excepción expresada en dos lenguajes diferentes: en el inciso a) se usa el lenguaje del civil law, y en el inciso b) el del common law ${ }^{42}$.

En el tráfico mercantil, la forma más habitual de indicar la irrevocabilidad de la oferta es cuando el oferente expresa que ella es irrevocable, bien mediante el uso de esta expresión u otras de análogo significado. Así, el oferente puede declarar expresamente que su oferta es irrevocable mediante cláusulas del tipo "garantizo mi oferta durante quince días", "mantendré esta oferta abierta durante un período de treinta días", "prometo no revocar esta oferta hasta [...]" y «oferta vinculante durante el período indicado", o finalmente mediante una frase del oferente en la que declare simplemente que su propuesta es irrevocable ${ }^{43}$. Estas hipótesis - que se corresponden dentro del articu-

42 Revocability of offer, en Bianca - Bonell (coord.), Commentary, op. cit., p. 156.

43 Igualmente los ejemplos que señala Eörsi, Revocability, op. cit., p.158: "Our offer is at any rate good till May 13" (oferta irrevocable); "I stand by my offer till I get 
lado de la Convención con la frase «la oferta no podrá revocarse, si indica [...] que es irrevocable» (Art. 16.2.a) CV) - constituyen los típicos, deseados y convenientes ejemplos de ofertas en las que se declara o indica indubitadamente el compromiso del oferente de no revocar su declaración de voluntad a través de expresiones claras o de palabras que se entienden generalmente en el tráfico como expresión de la voluntad de vinculación. En la lista de los supuestos mencionados, con excepción de uno, se ha añadido un plazo expreso durante el cual el oferente no puede revocar su propuesta. La Convención, sin embargo, no parece haber solucionado la cuestión del tiempo durante el cual la oferta permanece en situación de irrevocabilidad cuando no se ha fijado un término en la misma. No obstante, por analogía con el Art. $18.2 \mathrm{CV}$, ese plazo se determinará en función del estándar temporal de la razonabilidad.

Problema distinto es el que se presenta cuando el oferente no indica expresa ni tácitamente que la oferta es irrevocable, pero señala un plazo fijo durante el cual el destinatario puede aceptar la oferta. El señalamiento de un plazo fijo para aceptar (por ejemplo, «tiene veinte días para aceptar la oferta») indica -en muchos ordenamientos jurídicos- la voluntad del oferente de no revocar su oferta; en otros, por contra, no implica irrevocabilidad sino todo lo contrario. Bajo la normativa de la Convención no queda claro cuál es el significado de un plazo fijo para aceptar: si se quiere expresar que la oferta es irrevocable o que existe un plazo durante el cual el oferente puede aceptar la oferta, pasado el cual, la oferta caduca. Esta ambigüedad resulta de la propia redacción del Art. 16.2.a) que fue así redactado porque no se consiguió alcanzar un acuerdo acerca del significado de un plazo fijo para aceptar ${ }^{44}$. Fueron, pues, las diferencias entre los sistemas del common law y del civil law ${ }^{45}$

your answer» (oferta irrevocable), $\mathrm{y}$ "Our offer is not good after May 13" (oferta revocable).

44 Como se reconoce, the history of this article is dramatic. Eörsi realiza un excelente seguimiento del mismo (Revocability, cit., p.150). Honnold, a su turno, indica que la disputa en torno al plazo fijo de aceptación bien puede considerarse como un temporal en una tetera (Uniform Law, cit., p. 208 y ss.). Resalta también el sentido poco claro del precepto de la Convención Díez-Picazo, La formación del contrato, cit., p. 17.

45 Por ejemplo el derecho alemán establece en su parágrafo 145 BGB que la 
lo que impidió una solución unánime. La consecuencia de este compromiso será muy probablemente una interpretación divergente por parte de los tribunales, como así está sucediendo con la doctrina que examina esta cuestión. Así, mientras algunos autores consideran que una oferta que indique un plazo para aceptar está indicando expresa o tácitamente que es irrevocable. Otros autores señalan justamente la postura opuesta, esto es, que se trata simplemente de un plazo para aceptar, pero no un plazo de irrevocabilidad. La tesis que parece tener más éxito entre los comentaristas es la que señala que se habrá de dejar la cuestión a los tribunales ${ }^{46}$.

Otra forma en que la oferta puede ser considerada irrevocable, aun cuando el oferente no lo haya indicado en su oferta, deriva de la apariencia que crea en el destinatario de la oferta, de tal forma que éste confía en que la oferta es irrevocable y por ello lleva a cabo algún tipo de actuación relacionada con la oferta. En estas situaciones, el oferente no podrá revocar su oferta (Art. 16.2.b) CV) ${ }^{47}$. Muy probablemente las situaciones en las que se conceda un plazo fijo para aceptar, podrían crear esta apariencia en el destinatario, quien si realiza alguna actuación relacionada con la oferta, por ejemplo, inversiones en su empresa o compra de materiales, gastos de asesoramiento de peritos, abogados, etc., podrá gozar de la protección que la Convención le otorga.

En cualquiera de estos supuestos en que el oferente ha intentado revocar una oferta sin que pudiese hacerlo, el destinatario de la oferta podrá aceptarla ${ }^{48}$.

oferta es irrevocable una vez que es efectiva. En el UCC norteamericano, la oferta firme sólo es irrevocable (sólo por tres meses) cuando se cumplen determinadas circunstancias: que así lo indique el oferente por escrito y lo firme (sección 2-205 UCC).

46 Un amplio desarrollo de las diferentes tesis propuestas en Perales Viscasillas, La formación del contrato, op. cit., p. 427 y ss.

47 Esta excepción deriva de la doctrina del common law conocida como promissory estoppel o detrimental reliance doctrine. Pero, también, del sistema del civil law, de la doctrina conocida como venire contra factum propium, esto es, la de que nadie puede ir contra sus propios actos.

48 De acuerdo Honnold, Uniform Law, op. cit., p. 213 y ss.; en contra Heuzé, La vente internationale, op. cit., p. 142 y ss. 


\subsection{Invitación a ofrecer}

La Convención exige que la oferta se dirija a una o varias personas determinadas, presumiendo que existe una invitación ad offerendum cuando los destinatarios son el público en general. Es decir, que las llamadas ofertas al público no son ofertas en el sentido de la CV, a menos que el oferente indique claramente lo contrario, esto es, que expresamente señale que la declaración dirigida al público en general es una oferta. Ahora bien, entre las situaciones en que la oferta se dirige a "una o varias personas determinadas" y la invitación a hacer ofertas a la "generalidad del público»" ${ }^{49}$, existen ciertas situaciones intermedias en las que no queda claro cuál es su calificación jurídica. Nos referimos a los supuestos habituales de envío de catálogos, prospectos, folletos o instrumentos similares a número de personas identificadas por su nombre (nombre de la empresa o datos de identificación personal del empresario) y en los que constan los demás elementos del Art. $14^{\circ} \mathrm{CV}$. En nuestra opinión, esos supuestos han de tratarse como si fuesen invitaciones a hacer ofertas ${ }^{50}$, ya que en el tráfico comercial internacional, la utilización de esos instrumentos tiene un sentido perfectamente claro: exponer una información, incitar al destinatario a que realice una oferta o inducir a la lectura de la información que se envía.

49 En ocasiones puede ser difícil dilucidar lo que se entiende por personas determinadas y no determinadas. Se estima que la expresión "personas determinadas" incluye tanto las personas individuales como jurídicas e incluso, grupos que no posean personalidad, que sean uniones mercantiles, sociedades irregulares o grupos de negocios. Estos conjuntos de personas deben considerarse como personas determinadas, tanto si la oferta se dirige a nombre de uno de ellos como si se dirige a todos, recuerda Díez-Picazo, Formación del contrato, op. cit., p. 12.

50 A favor: Honnold, Uniform Law, cit., p. 195 y ss.; Neumayer - Ming, Convention de Vienne sur les contracts de vente internationale de marchandises, Lausanne, 1993, p. 137 y ss.; Garro - Zuppi, Compraventa, op. cit., p. 104; Díez-Picazo, La formación del contrato, op. cit., p. 12; Id., Fundamentos, op. cit., p. 291. En contra se entiende que el envío de catálogos a compradores específicos, esto es, dirigido a una o varias personas en particular por medio de una lista restringida de direcciones (restricted mailing list) podría ser considerado como una oferta a cada uno de los posibles compradores. Así el comentario de la Secretaría al actual artículo $14^{\circ}, \$ 3$; Sono, Formation, op. cit., p. 211 y ss.; Heuzé, La vente internationale, op. cit., p. 195 y ss.; Audit, La vente internationale, op. cit., p. 57 y ss. 


\section{La aceptación}

La aceptación es aquella declaración de voluntad o acto del destinatario de una oferta que manifiesta el asentimiento o conformidad con ésta. Constituye, en sentido propio, una declaración de voluntad negocial clara e incondicionada ${ }^{51}$. Como bien apunta Farnsworth, la aceptación es el tramo final del período de formación del contrato y no puede contener ningún tipo de condicionamiento ${ }^{52}$. La aceptación puede realizarse de tres formas: mediante una declaración, mediante un acto o, incluso, mediante su silencio o inacción. A menos que el oferente prescriba alguna forma determinada de aceptación, el destinatario de la oferta es libre de aceptarla, sea por escrito (carta, telegrama, télex, fax, e-mail, etc.) o verbalmente (estando las partes presentes o por teléfono, radio, etc.). En ambos circunstancias, para que la aceptación sea efectiva y, en consecuencia, perfeccione el contrato, debe llegar al oferente en el plazo establecido en la oferta o, en su defecto, en un plazo razonable (Art. 18.2 CV). Por plazo razonable, debe entenderse aquel que resulta del cumplimiento de las reglas de diligencia y buena $\mathrm{fe}^{53}$.

\subsection{Aceptación verbal}

El Art. 18.2 CV es suficientemente claro en el sentido que la aceptación de las ofertas verbales tiene que ser inmediata, a menos que de las circunstancias resulte otra cosa. Aquí el carácter inmediato no significa solamente sin demora, sino también sin solución de continuidad temporal. Son ofertas verbales, en el sentido de esta norma, todas aquellas en las que no existe un texto escrito de comunicación y en las que, no

51 Cfr. Díez-Picazo, La formación del contrato, op. cit., p. 12; Perales Viscasillas, La formación del contrato, op. cit., p. 481 y ss.

52 Acceptance, en Bianca - Bonell (coord.), Commentary, op. cit., p. 171 y ss.

53 Es claro que no puede someterse al oferente a una espera indefinida, por lo que, aun cuando éste no haya retirado ni revocado la oferta, el transcurso del tiempo por sí solo debe permitirle considerarse liberado de ella. Al mismo tiempo, el aceptante debe quedar cubierto de las posibilidades de abuso por parte del oferente en la posibilidad de considerar la aceptación como tardía. La idea de plazo razonable trata de equilibrar una y otra exigencia, explica Díez-Picazo, La formación del contrato, op. cit., p. 21; Id., Comentario al artículo $18^{\circ}$, op. cit., p. 183. 
encuentran aplicación las reglas sobre el contrato entre ausentes. En efecto, debe tratarse de personas que se encuentren ante un sistema de comunicación que permita que las mencionadas comunicaciones sean ininterrumpidas y que no existan intervalos de tiempo entre los diferentes tramos de ella. Por ende, este precepto resulta aplicable no sólo a los contratos entre personas presentes, sino también a las comunicaciones telefónicas y a todas aquellas en que se utilice cualquier otro sistema que permita la respuesta inmediata y la comunicación ininterrumpida. No se aplica, en consecuencia, a aquellas comunicaciones que, no obstante ser ininterrumpidas, incorporen a su sistema un texto escrito ${ }^{54}$.

La citada regla general tiene una excepción: que de las circunstancias resulte otra cosa. La circunstancia más usual que varía la exigencia de una respuesta inmediata viene constituida por el consentimiento del oferente a una respuesta posterior, bien por la petición del destinatario de ese período de tiempo adicional, bien por la concesión del mismo en la oferta.

\subsection{Aceptación mediante actos}

La declaración de aceptación se realiza, en lo habitual, mediante una declaración oral o escrita, pudiendo igualmente consistir en actos que indiquen asentimiento a una oferta (por ejemplo, mediante el envío de las mercancías y el pago del precio). En estos casos se establece que no será necesario enviar una declaración, puesto que el mismo acto del envío o el pago del precio perfecciona el contrato ${ }^{55}$. Ahora bien para

54 Cfr. Díez-Picazo, Comentario al artículo $18^{\circ}$, op. cit., p. 184; Id., Fundamentos, op. cit., p. 308.

55 No obstante algunos autores demandan el envío de una comunicación cuando la llegada de las mercancías se va a producir en un espacio dilatado de tiempo, si bien no la exigen en caso contrario. Así Honnold, Uniform Law, op. cit., p. 223 y ss.; Enderlein - Maskow, International Sales Law: United Nations Convention of Contracts for the International Sale of Goods, New York, 1992, p. 91 y ss. En contra: Perales Viscasillas, La formación del contrato, op. cit., p. 534 y ss. La Cámara Nacional en lo Comercial, sala E, 14 octubre 1993 (Argentina) (Carlos III), ha entendido aceptada una oferta-factura de forma implícita por el envío del formulario firmado por el comprador al banco encargado de financiar la operación. Se ha entendido, en consecuencia, que se ha realizado por el comprador un acto referido al pago del precio equivalente a la aceptación del Art. 18.3 CV. 
que pueda aceptarse mediante actos de ejecución sin necesidad del envío de una comunicación al oferente, es necesario que la oferta lo autorice (por ejemplo, comience la fabricación, envíe inmediatamente, compre en mi nombre sin demora ${ }^{56}$, o indicando una cuenta corriente para que el comprador pueda hacer efectivo el precio) o que así se permita por virtud de las prácticas establecidas con anterioridad por los contratantes o por los usos (Art. 18.3 CV). La oferta también se acepta concluyentemente mediante el recibo de las mercancías sin objeción alguna en cuanto a los términos de la oferta ${ }^{57}$.

El silencio o la inacción, por sí solos, no implican aceptación (Art. 18.1 CV). En términos generales, el silencio es una actitud que, claramente, no posee ninguna significación objetiva. El que guarda silencio no declara nada y, por ello, no puede decirse que callando se manifieste una voluntad negocial. En rigor, el silencio más que declaración de voluntad es omisión de declaración ${ }^{58}$. Empero, el silencio o la inacción, junto con otros factores, sí pueden significar aceptación de la oferta en algunos casos. Esos factores son los siguientes: a) disposiciones legales, como el Art. 19.2 o el Art. $21^{\circ} \mathrm{CV}$; b) usos y prácticas establecidas entre las partes, por ejemplo porque habitualmente no se contesta a la oferta-pedido, sino que se procede al envío de las mercancías; c) la existencia de un deber de hablar o contestar puede hacer que el silencio o inacción se considere como aceptación. Así se ha entendido en uno de los primeros casos que aplicó la Convención de Viena en los Estados Unidos: Filanto v. Chilewich. Efectivamente, el U.S. District Court for the Southern District of New York, en su sentencia de 14 abril $1992^{59}$, se enfrenta a la cuestión de si debía entenderse incorporada al

56 Comentario de la Secretaría al actual Art. 18.3 CV, $\$ 11$. No obstante, parte de la doctrina entiende que un lenguaje de ese tipo no es lo suficientemente claro como para dispensar de la comunicación de la aceptación. Así Farnsworth, Acceptance, op. cit., p. 173; Herber - Czerwenka, Internationales Kaufrecht, Kommentar zu dem Übereinkommen der Vereinten Nationem vom 11 april 1980 úber Verträge über den Internationalen Warenkauf, München, 1991, p. 99.

57 LG Krefeld, 24 noviembre 1992 (Alemania) (PACE) (UNILEX).

58 Díez-Picazo, La formación del contrato, op. cit., p. 23; Id., Comentario al artículo $18^{\circ}$, op. cit., p. 185.

$59 \mathrm{Vid}$. acerca de la primera sentencia declarando una aceptación por el silencio del destinatario de la oferta: Perales Viscasillas, "La perfección por silencio de la compraventa internacional en la Convención de Viena de 1980", en Derecho de los 
contrato una cláusula de sometimiento al arbitraje de la Cámara de Comercio e Industria de Moscú. El tribunal acude primero al artículo II de la Convención de Nueva York de 1958 y en orden a determinar si se produce un acuerdo acerca de dicha cláusula, procede a examinar las reglas sobre formación del contrato en la Convención de Viena de 1980. De conformidad con ellas entiende sobre la base de la pasividad o silencio del destinatario de la oferta (Art. 18.1 CV) que la cláusula de arbitraje debe ser entendida como parte integrante del contrato. La decisión es todavía más lógica porque el silencio o la pasividad están reforzadas en el caso concreto por el inicio en la ejecución del contrato (apertura del crédito documentario).

En cualquier caso, no se podrá conceder valor alguno a una frase en la oferta en la que se establezca que el silencio del destinatario se considerará como una aceptación ${ }^{60}$, ya que de lo contrario se vincularía al destinatario al nacimiento de un contrato por una simple declaración unilateral del oferente.

\subsection{Aceptación tardía}

Como hemos apuntado, la aceptación, para ser efectiva y, por ende, perfeccione el contrato, debe llevarse a cabo antes que la oferta haya caducado o deba considerarse caducada por el transcurso del tiempo. En esta línea, el Art. $18^{\circ} \mathrm{CV}$ establece una regla de caducidad de la oferta por el transcurso del tiempo, que puede ser la expiración del plazo fijado por el oferente o el transcurso del tiempo razonable. Según esto, la aceptación que llegue al oferente fuera de los plazos indicados, no es aceptación eficaz y, como tal, no permite considerar formado el contrato. En el mejor de los casos tendría que ser considerada como una contraoferta susceptible de una nueva aceptación por el primitivo oferente; sin embargo, debemos recordar que esta regla de caducidad está establecida en interés del oferente, de manera que puede constituir

Negocios, Madrid, 1995, núm. 52, p. 9 y ss.; también en Pace, comentando el caso Filanto S.p.A. v. Chilewich International Corp., 984 F. 2d 58 (2d Cir. 1993) U.S. District Court for the Southern District of New York, 14 abril 1992, (Estados Unidos) (Pace) (UNILEX).

60 Precisamente el artículo 2.2 LUF así lo establecía. 
una facultad o, mejor todavía, un derecho potestativo del oferente aceptar la efectividad de la aceptación tardía ${ }^{61}$.

El Art. $21^{\circ} \mathrm{CV}$ regula los efectos de una declaración de voluntad que en el ámbito del texto uniforme tiene dos sentidos perfectamente claros y diferenciados que reciben, no obstante, una denominación unitaria: aceptación tardía. A través de esta expresión se quiere designar ciertas situaciones que atienden al destino de una declaración de aceptación que llega al destinatario-oferente fuera del plazo establecido en la oferta o el razonable para que la aceptación surta efectos a causa de un envío extemporáneo, así como aquellas otras circunstancias excepcionales que revelan una llegada tardía de la aceptación derivada de ciertas irregularidades en el curso normal de la transmisión de una declaración de voluntad. Tales situaciones, de conformidad a la norma citada, pueden encontrar efectividad si el oferente inmediatamente le envía al destinatario una comunicación aceptando, no obstante estar fuera del término establecido. De este modo, a pesar del carácter tardío de la aceptación, el contrato puede considerarse formado si hay un acto de aprobación o de conformidad del oferente, que el Art. $21^{\circ} \mathrm{CV}$ califica como una «información», aunque claro está que es un acto de voluntad del oferente. No se trata, pues, de un acto de aceptación de una contraoferta, sino de un acto que dota de efectividad a la aceptación pese a su carácter tardío. Esta distinción tiene cierta importancia en orden a la determinación del momento en que el contrato debe considerarse formado, porque al dotarse de efectividad a una aceptación tardía, el contrato no queda formado cuando se remite o se recibe esta declaración de conformidad, sino con la llegada de la aceptación, de manera que la aprobación posee, si se quiere, un cierto carácter retroactivo $^{62}$.

61 Cfr. Díez-Picazo, Fundamentos, op. cit., p. 315; Id., Formación del contrato, op. cit., p. 29.

62 Cfr. Díez-Picazo, Fundamentos, op. cit., p. 316. La aprobación o conformidad del oferente a la aceptación tardía puede realizarse verbalmente o a través de medios de comunicación escritos, cualquiera que sea el medio que utilice. Debe realizarse sin demora, lo que significa sin retraso imputable al oferente y a través de medios de comunicación que faciliten la rapidez de la transmisión. Si la aprobación de la aceptación tardía fue a su vez tardía, se encontraría justificado que el aceptante pudiera rechazar la formación del contrato, explica el citado autor (Formación del contrato, op. cit., p. 30). 
En suma, la Convención, con la inclusión del Art. $21^{\circ}$, busca dar la oportunidad al oferente de decidir si desea, ante una aceptación retrasada y, por tanto, incapaz de surtir los efectos propios de una aceptación temporánea, perfeccionar el contrato ${ }^{63}$. Lo contrario sería absurdo desde un punto de vista lógico, en atención a que si el oferente quiere seguir vinculado no se le debe negar esa posibilidad por un mero defecto temporal que él está dispuesto a soportar, y jurídico, debido a que prácticamente se llegaría al mismo resultado aplicando la sistemática sobre la que se asientan las reglas sobre la oferta y la aceptación en la Convención.

\section{La contraoferta}

La declaración de aceptación ha de coincidir en todos y cada uno de sus términos con la oferta para que pueda perfeccionar el contrato (Art. 19.1 CV); se trata de lo que se conoce como regla del espejo (mirror image rule), ya que la aceptación debe ser como el reflejo de la oferta en el espejo ${ }^{64}$. Se establece como excepción la posible introducción de

63 Cfr. Perales Viscasillas, La formación del contrato, op. cit., p. 597. Puede cuestionarse, dice Díez-Picazo, si el carácter tardío del retraso de que habla el Art. $21^{\circ}$, tiene que ser un retraso no sustancial o no demasiado grande o si puede aplicarse la norma cualquiera que sea la consideración que el retraso merezca. La norma no establece ninguna distinción y resulta muy difícil poderla introducir. Lo decisivo no es tanto la consideración del retraso en sí mismo como la rapidez del oferente en la comunicación de asentimiento. Tampoco entran en consideración las causas que pueden haber originado el retraso, ni imputabilidad o falta de imputabilidad de las mismas al oferente (Comentario al artículo $21^{\circ}$, op. cit., p. 198).

64 Es consecuencia de esta forma de entender las cosas que si el destinatario de la oferta acepta el contrato ofrecido, pero introduce en su comunicación un elemento nuevo o términos que suponen modificación de la propuesta, no hay verdadera aceptación, sino una nueva oferta (contraoferta). Los anglosajones señalan que se produce entonces una inversión y pasa a ser oferente el destinatario de la anterior oferta. Se habla, por ello, de last shot rule o «regla de la última palabra», señala Díez-Picazo, La formación del contrato, op. cit., p. 24; Id., Comentario al artículo $18^{\circ}$, op. cit., p. 187. Un importante análisis de estas reglas y las críticas que le han formulado puede verse en Durany Pich, «Sobre la necesidad de que la aceptación coincida en todo con la oferta: el espejo roto", en Anuario de derecho civil, Madrid, 1992, t. XLIV, fasc. III, p. 1083 y ss. 
términos en la aceptación que no alteren sustancialmente a la oferta. En este caso, la aceptación valdrá como tal y el contrato comprenderá los términos de la oferta mas aquellos incluidos en la aceptación que no los alteren sustancialmente y siempre que éstos no hayan sido objetados por el oferente sin demora injustificada, bien verbalmente, bien por el envío de una notificación (Art. 19.2 CV). Por el contrario, si el elemento que se introduce en la declaración de aceptación adiciona otros términos, modifica los términos de la oferta o introduce cualquier otro tipo de limitación en la oferta que la altere sustancialmente, entonces el contrato no podrá entenderse perfeccionado, y la respuesta a la oferta se transforma en contraoferta, si reúne desde luego los requisitos que la Convención demanda para considerar a una oferta como completa (Art. $14^{\circ} \mathrm{CV}$ ).

En orden a determinar cuándo un elemento introducido en la aceptación altera sustancialmente a la oferta y, por ende, perfecciona o no el contrato, se proporciona todo un listado de términos. Este listado es un mero ejemplo, como se deriva de la expresión del Art. 19.3 CV «en particular». Además la lista tiene un carácter presuntivo («se considerará»). La lista incluye los siguientes elementos: precio (únicamente las variaciones relativas al monto total del precio ofertado, incluyendo las cláusulas de variación del precio por el incremento en los costos ${ }^{65}$, pago (modalidades ${ }^{66}$, lugar y tiempo), calidad y cantidad de las merca-

65 Este caso se ejemplifica muy bien con un supuesto real. Una sociedad francesa realiza una oferta de compra de componentes electrónicos indicando "al precio previamente indicado por el proveedor que se revisará en función de los cambios de mercado». Este pedido es confirmado por la destinataria, una sociedad alemana, indicando: «los precios son revisables al alza sobre la base convenida en función del mercado". En este caso, si bien el tribunal no entra a discutir la esencialidad de la modificación, parece entender que no es esencial. Tribunal de Casación de París, 4 enero 1995 (Francia) (PACE) (UNILEX).

66 LG Giessen, 22 diciembre 1992 (6 0 66/92), en apelación OLG Frankfurt am Main, 4 marzo 1994 (Alemania) (PACE) (UNILEX), han entendido que una respuesta a la oferta en que se modifican las modalidades de pago es una contraoferta (se indicaba que el pago había de ser por adelantado o mediante una garantía bancaria). Asimismo una respuesta a un pedido donde se señalaba "pago anticipado" cuando la oferta indicaba expresamente "envío contra recmbolso": OLG Hamm, 21 marzo 1979 (Alemania) (PACE) (UNILEX), enjuiciando un litigio en la LUF. 
derías ${ }^{67}$, lugar y fecha de la entrega ${ }^{68}$, grado de responsabilidad de una parte con respecto a la otra ${ }^{69}$, y solución de las controversias. No obstante, es muy posible que el listado se considere por los tribunales en el sentido de que los términos allí mencionados que se añaden a una respuesta a la oferta la alteran sustancialmente en cualquier caso y viceversa, especialmente, en el segundo caso, cuando la oferta nada dice. En caso contrario, parece que la alteración se considerará sustancial. Por ejemplo, se ha señalado que es una variación sustancial el rechazo del embalaje de beicon en "bolsas de polietileno" mediante el contra ofrecimiento de un método de embalaje "a granel $»^{70}$. La interpretación de que se considere como sustancial ha de hacerse con carácter restringido con el objeto de facilitar una regla de interpretación clara ${ }^{71}$.

La lista que se ofrece contiene elementos de carácter sustantivo que se refieren a los derechos y obligaciones que surgen del contrato de compraventa, lo que elimina de la consideración de elementos sustanciales, en primer lugar, a la iniciativa del destinatario de la oferta por volver a las negociaciones ${ }^{72}$, en segundo lugar, a los pequeños cam-

$67 \mathrm{Si}$ la oferta indica que la calidad del cristal ha de ser "Fiolax", mientras que el destinatario de la oferta responde que la calidad ha de ser "Duran", entonces el contrato no puede entenderse perfeccionado, ya que es una modificación sustancial (Art. 19.3): OLG Frankfurt am Main, 31 marzo 1995 (25 U 185/94) (Alemania), que se aparta de lo sostenido en instancia (LG Kassel, 14 julio 1994 (11 O 4279/93) (Alemania).

68 Una respuesta a la oferta de modificación del contrato que indique (entrega entre el $1^{\circ}$ de julio y el 15 de agosto), cuando la oferta indicaba (entrega julio, agosto, septiembre o octubre) es una contraoferta, ya que se modifican los plazos de entrega de las mercancías (OLG München, 8 febrero 1995 (Alemania) (PACE) (UNILEX).

69 LG Baden-Baden, 14 agosto 1991 (4 0 113/90) (Alemania) ha entendido que una cláusula por la que se indica que se deberá avisar de la falta de conformidad de las mercancías en el plazo de treinta días a contar desde la fecha de la factura no puede considerarse que altere sustancialmente a la oferta; además parece admitirse que las cláusulas previamente redactadas que aparecen impresas se convierten en contenido del contrato.

70 OLG Hamm, 22 septiembre 1992 (Alemania) (PACE) (UNILEX).

71 Algo en lo que está de acuerdo la mayor parte de la doctrina, por todos: Enderlein - Maskow, International Sales Law, op. cit., p. 100.

72 Cfr. Durany Pich, Sobre la necesidad de que la aceptación, op. cit., p. 1083; Díez-Picazo, La formación del contrato, op. cit., p. 26. Vid. en la jurisprudencia: Pretura Circondiarale di Parma, sez. di Fidenza, 24 noviembre 1989 (Italia) (PACE) (UNILEX). 
bios de redacción en relación con la oferta que en nada afecten a la aceptación. Por ejemplo, una aceptación en la que se añaden ciertas quejas («acepto porque necesito urgentemente las mercancía»; "de acuerdo, pero esperaba un acuerdo más satisfactorion); algunas recomendaciones o preguntas («acepto, que el pago sea en billete de 10.000 pesetas»; «acepto, ¿sería posible incluir una cláusula de arbitraje?»); algunas peticiones («que la aceptación se mantenga reservada hasta que se anuncie por ambas partes públicamente» $)^{73}$. Asimismo, tampoco parece que pueda considerarse como una alteración sustancial el hecho de añadir en la respuesta a la oferta algún término que se entiende parte integrante de la oferta, y como tal entraría a formar parte del contenido contractual como parte del derecho dispositivo aplicable; todo esto, porque se trata de una práctica que es habitual entre las partes o un uso que les vincula, o porque así se deriva de la buena fe (por ejemplo, si se añade en la aceptación "de acuerdo con el estándar de calidad usual».

Por último, una modificación de la oferta que por su tenor beneficie al oferente tampoco debería considerarse sustancial ${ }^{74}$. Sería el caso en que una oferta ha establecido que el pago se realizará a plazos y el destinatario de la oferta responde afirmativamente al tiempo que indica que el pago lo realizará al contado. Tampoco estaremos ante una contraoferta cuando el oferente haya previsto que el destinatario pueda variar o modificar alguno de los elementos de la oferta $o$, incluso, que pueda elegir alguno de ellos a su conveniencia.

73 Así lo entendió el Tribunal Metropolitano de Budapest, 10 enero 1992 (Hungría) (PACE) (UNILEX) en el caso Pratt and Whitney v. Malev Hungarian Airlines, y ello porque dicha petición no puede considerarse como una adición, limitación o modificación.

74 Así parece sugerirlo el Oberster Gerichtshof, 20 marzo 1997 (Austria) (2 Ob $58 / 97 \mathrm{~m}$ ), que si bien envía la cuestión a la determinación por parte del tribunal inferior, declaró que las alteraciones que se efectuaban únicamente en favor de la otra parte no requerían una aceptación expresa. En el caso concreto, la oferta del comprador ruso indicaba 10.000 toneladas $+/-10 \%$ de monoamoniofosfato (MAF) con la especificación "P $20552 \%+1-1 \%$, min 51\%. El vendedor aceptó la entrega de 10.000 toneladas $+/-5 \%$ MAF con la especificación "P $20552 \%+/-5 \%$, min $51 \%$. 


\section{Perfección del contrato: momento y lugar}

El momento en el cual el contrato de compraventa internacional de mercaderías se perfecciona en el marco de la Convención de Viena se recoge en la penúltima de las disposiciones dedicadas a la perfección del contrato. Señala el Art. $23^{\circ} \mathrm{CV}$ que «el contrato se perfeccionará en el momento de surtir efecto la aceptación de la oferta conforme a lo dispuesto en la presente Convención" ${ }^{75}$. La versión española, como podemos observar, siguiendo la tradición, utiliza el vocablo «perfección", a diferencia de las versiones inglesa y francesa que hablan de conclusión "is concluded, est conclu».

La disposición más importante que se relaciona con la citada norma es el Art. 18.2, que se encarga de establecer la regla general acerca del momento de perfección del contrato en la CV. Dice este artículo que "la aceptación de la oferta surtirá efecto cuando llegue al oferente», bien en el plazo por él fijado o, en su defecto, dentro de un plazo razonable ${ }^{76}$; cuestión que el Art. $24^{\circ} \mathrm{CV}$ se encarga de aclarar a efectos interpretativos, acogiendo para ello la teoría del conocimiento para las declaraciones realizadas de forma oral y la teoría de la recepción para las declaraciones escritas. Así, pues, el sistema general del cual parte la Convención es el de indicar que las declaraciones de voluntad y en general cualquier manifestación de intención se tornan perfectas en el

75 La presencia de esta norma en la CV ha dividido a los comentaristas: para unos, el contenido de este precepto no era absolutamente necesario porque se encuentra sobrentendido en los artículos anteriores (Díez- Picazo, Comentario al artículo $23^{\circ}$, op. cit., p. 201), para otros, en cambio, determinar este momento es importante puesto que otros artículos de la Convención se refieren a él (Adame Goddard, el contrato, op. cit., p. 114).

76 Por un plazo razonable para aceptar parece que habrá de entenderse, al menos, el tiempo de viaje de la oferta, el tiempo necesario para reflexionar acerca del contrato que se ofrece, así como el tiempo necesario para que la declaración de aceptación llegue al oferente. En cualquier caso, el artículo 18.2 somete a este plazo razonable a la guía de interpretación que marcan las circunstancias de la transacción y la rapidez de los medios de comunicación empleados por el oferente. Entre las circunstancias que rodean a la transacción, que habrán de tenerse en cuenta, de cara a calibrar el plazo de aceptación, están la naturaleza de las mercancías: sometidas a un rápido deterioro físico (mercancías perecederas) o económico (mercancías sometidas a rápidas fluctuaciones en el precio); el cumplimiento de ciertas exigencias de tipo administrativo (licencias de exportación o importación). 
momento de su llegada, esto es, cuando son recibidas (entregadas) o conocidas (comunicadas verbalmente), y no cuando son declaradas o emitidas. El uso del término «llega» empleado por la Convención (reaches en la versión oficial en inglés) se corresponde en el UCC norteamericano con la definición de receives (UCC 1-201), con lo que se conoce en el sistema alemán como zugehen, y, en general, con lo que nosotros llamamos teoría de la recepción por lo que respecta a las declaraciones escritas y teoría del conocimiento para las declaraciones orales. La perfección del contrato, sin embargo, puede truncarse si el aceptante retira su aceptación antes de que surta efecto o en ese momento (Art. 220 $\mathrm{CV})$. Se evidencia que, al igual que sucede con la retirada de la oferta, ello sólo es posible cuando la declaración de aceptación se ha enviado por correo o telégrafo.

Es posible, igualmente, que el contrato se perfeccione, no obstante que la aceptación llegue fuera del plazo legal o contractual. Se trata de aceptaciones tardías que se regulan en el Art. $21^{\circ} \mathrm{CV}$. Existen a estos efectos dos posibles situaciones: a) una aceptación que llega tarde por culpa del destinatario de la oferta - es decir, se presume que el retraso ha sido causado por el destinatario de la oferta, bien porque envía la aceptación fuera de plazo o sin tener en cuenta el tiempo necesario para que llegue al oferente - (Art. 21.1); y b) una aceptación que llega tarde por causa de alguna irregularidad conectada al medio de transmisión, por ejemplo porque existe una huelga de los empleados de correos (Art. 21.2). En el primer caso, la aceptación no puede perfeccionar el contrato; no obstante, el oferente puede informar oralmente al destinatario o enviarle una comunicación validando la aceptación, por lo que el contrato se entiende perfeccionado desde ese momento ${ }^{77}$. En el segundo caso, la presunción es la contraria a la establecida para la situación anterior y por ello se considera que la aceptación es capaz de perfeccionar el contrato, pero se faculta al oferente a que declare que el mismo no se perfecciona, en cuyo caso, ha de informar de su intención al destinatario de la oferta, sin demora, verbalmente o por escrito. Si el oferente no se comunica con el destinatario, entonces el contrato se perfecciona con la llegada de la aceptación; nótese, no obstante, que en la práctica se extiende hasta el tiempo límite de que dispone el

77 En contra, el comentario de la Secretaría, $\$ 3$ y buena parte de la doctrina. Por todos, Díez-Picazo, La formación del contrato, op. cit., p. 30. 
oferente, un plazo que se cualifica por la expresión «sin demora» para informar al aceptante de la caducidad de la oferta.

Se advertirá que cuando el oferente ha fijado un plazo para aceptar la oferta, el destinatario ha de aceptarla dentro de ese plazo. Algún problema se presenta en los casos en que el oferente no especifica el término inicial (dies a quo) ni el final del cómputo del plazo para aceptar, por ejemplo, que únicamente haya indicado que la oferta puede aceptarse en un mes. En estos casos, la Convención establece que cuando el plazo de aceptación se ha fijado en una carta o en un telegrama, el cómputo del mismo comienza desde el momento de la entrega (en el caso del telegrama) o desde el momento que figure en la carta o, en su defecto, desde la fecha que figure en el sobre (en el caso de correspondencia postal). Si se trata de medios de comunicación instantáneos, entonces el plazo comienza desde que la oferta llega al destinatario (Art. 20.1 CV). Además, en el cómputo se incluyen los días feriados oficiales o no laborables, pero si la aceptación no puede ser entregada en la dirección del oferente el día del vencimiento del plazo, por ser ese día feriado oficial o no laborable en el lugar del establecimiento del oferente, el plazo se prorrogará hasta el primer día laborable siguiente (Art. 20.2 CV). Por último, vale indicar que estas normas relativas al cómputo del plazo de aceptación pueden ser útiles para aplicarlas analógicamente a cualquier plazo establecido en la parte III de la Convención, cuyo cómputo no se haya establecido.

En cuanto al lugar de perfección del contrato, la Convención no contiene ninguna norma ni ningún principio general que permita determinar ese lugar. Esto nos lleva a señalar que, de conformidad con el Art. 7.2. CV habrá de acudirse al derecho interno no uniforme que resulte aplicable ${ }^{78}$. Por ejemplo, si resulta aplicable el español (Art. $1262^{\circ}$ c.c.) o el peruano (Art. $1373^{\circ}$ c.c.), el lugar de perfección del contrato vendrá determinado por el lugar en que se hizo la oferta.

78 Así lo indica, además, la historia legislativa. Cfr. Perales Viscasillas, La formación del contrato, op. cit., p. 265; Farnsworth, "Time of conclusión of contract", en Bianca - Bonell (coord.), Commentary, op. cit., p. 200 y ss.; Fernández de la Gándara - Calvo Caravaca, "El contrato de compraventa internacional de mercancías», en Fernández de la Gándara - Calvo Caravaca (dir.), Contratos internacionales, Madrid, 1997, p. 215. 


\section{Formación del contrato a través de representantes}

Es habitual que en el comercio internacional, compradores y vendedores no negocien por sí mismos el contrato sino que lo hagan a través de terceras personas: agente, representante $\mathrm{o}$, en general, cualquier tercero que se halle vinculado a alguna de las partes. Terceros que, además, pueden desempeñar algún papel durante la fase de ejecución del contrato, por ejemplo, porque se les comisiona para cobrar el importe del precio del contrato de compraventa. La Convención presupone que el proceso negociador se lleva a cabo directamente entre las partes contratantes; no obstante, el cumplimiento de la necesidad de llegada de cualquier indicación de asentimiento puede producirse mediante la entrega y recepción de la comunicación por terceras personas distintas del oferente y del aceptante. Si ello es así, es importante que la parte que se comunica con ese tercero se asegure de que la comunicación le llega personalmente a su contraparte.

Una ilustración de los problemas que pueden surgir nos la ofrecen los tribunales alemanes, donde en relación con la noticia que el comprador ha de enviar al vendedor por la falta de conformidad de las mercaderías (Art. 39.1 CV), se ha entendido que cuando dicha noticia no se da personalmente al vendedor sino a un empleado del vendedor por teléfono, el cual no estaba autorizado a recibir comunicaciones, pero que aseguró que haría llegar el mensaje al vendedor, lo cual aparentemente nunca sucedió, el comprador ha de asegurarse de que el vendedor la reciba personalmente ${ }^{79}$.

Ha de tratarse en todo caso de un representante autorizado ${ }^{80}$. La suficiencia del poder de representación habrá de resolverse conforme al

79 LG Bochum, 24 enero 1996 (Alemania) (PACE) (UNILEX).

80 Lo reconoce de esta forma el comentario de la Secretaría al actual artículo $24^{\circ}$ $\mathrm{CV}, \$ 6$, que añade, además, que las cuestiones acerca de cuáles son las personas que pueden estar habilitadas para representar al destinatario deben resolverse de conformidad con la ley nacional aplicable. El LG Kassel, 15 febrero 1996 (Alemania) (PACE) (UNILEX) ha tenido la ocasión de resolver un litigio entre un vendedor italiano y un comprador alemán que concluyeron un contrato de compraventa de baldosas de mármol, que habían de ser fabricadas por el vendedor de acuerdo con las especificaciones proporcionadas por el comprador. El comprador se negó a pagar el precio alegando que había notificado por teléfono la falta de conformidad de las mercaderías al mediador (tercero independiente) que actuó durante la formación del 
derecho nacional no uniforme que resulte aplicable al tratarse de una cuestión de validez que el Art. $4^{\circ} \mathrm{CV}$ reenvía para su enjuiciamiento al mismo $^{81}$.

\section{Modificación del contrato}

La Convención mediante el Art. $29^{\circ}$ regula expresamente la modificación del contrato. De entrada, la regla del Art. 29.1 CV establece que «el contrato podrá modificarse o extinguirse por mero acuerdo entre las partes». Mediante esta norma se acercan los dos grandes bloques de sistemas jurídicos, el civil law y el common law, privando de virtualidad a la consideration como elemento imprescindible para que se pudiese producir la modificación del contrato ${ }^{82}$. En los ordenamientos pertenecientes al sistema del civil law, la modificación de los contratos de compraventa no ofrece ningún problema, pues éstos son negocios en los que basta para su modificación o extinción el mero consentimiento

contrato. No obstante, el vendedor nunca recibió dichas quejas. El tribunal indicó que la comunicación de la falta de conformidad al tercero mediador que no tiene relación alguna con el vendedor no puede considerarse como «medios adecuados a las circunstancias» (Art. 270 CV), por lo que el comprador tiene que soportar el riesgo de no haber comunicado al vendedor la falta de conformidad de las mercancías.

81 Así lo ha entendido recientemente el Kammergericht Berlin, 24 enero 1994 (Alemania) (PACE) (UNILEX). Asimismo la doctrina, Neumayer - Ming, Convention de vienne, op. cit., p. 200; Bydlinski, Das allgemeines, op. cit., p. 64; Id., "Der Vertragsschluss nach der Wiener UN-Kaufrechtskonvention in Komparativer Betrachtung", en Archivum huridicum Cracoviense, 1985, vol. XVIII, p. 143 y ss. Díez-Picazo, por su parte, indica que se aplican las reglas generales de los contratos cuando la persona que haya emitido la oferta sea un representante legal o voluntario, un apoderado, un agente o el órgano de una persona jurídica. Además señala a continuación que compete al aceptante reclamar un examen de los poderes, aunque, según los casos, podrá funcionar un apoderamiento derivado de hechos concluyentes (La formación del contrato, op. cit., p. 11).

82 El Art. 29.1, señala Cabanillas, tiene por objeto principal descartar la exigencia de la consideration, vigente en el sistema del common law, en el que se requiere que la alteración no perturbe el equilibrio contractual, tal como éste se presenta en el momento de la celebración del contrato. Un acuerdo no puede implicar, sin contrapartida, un agravamiento de las obligaciones de una sola de las partes (Comentario al artículo $2^{\circ}$, en Díez-Picazo (dir.), La compraventa internacional, op. cit., p. 235). 
de los contratantes sin necesidad de que se observe, en principio, requisito formal alguno.

Basta, pues, en el ámbito de la Convención, el mero acuerdo de las partes contratantes (verbal, por escrito, por actos o, incluso, por el silencio o inacción) para que la modificación (la variación de alguno de los términos del contrato previamente acordado) o la extinción (la total terminación de la relación contractual que liga a la partes del contrato) se produzcan ${ }^{83}$. A los efectos aplicativos de esta disposición es indiferente que una de las partes obtenga una ventaja sobre la otra, por ejemplo, que se incremente el precio sin modificar la cantidad y al contrario $^{84}$.

83 Siempre teniendo en cuenta que existan factores suficientes que puedan otorgar el valor de aceptación al silencio o inacción del destinatario de la oferta, como se confirma, además, por la jurisprudencia: Handelsgericht des Kantons Zürich, 10 julio 1996 (Suiza) (HG 940513). En principio, el silencio de la otra parte contratante no equivale a un acuerdo sobre las modificaciones realizadas en el contrato, apunta Cabanillas, Comentario al artículo $29^{\circ}$, op. cit., p. 235.

84 Precisamente una "pretendida" modificación del precio del contrato que significaba una reducción del precio sin la correlativa disminución de la cantidad, era el supuesto de hecho discutido por la Cour d'appel de Grenoble (Chambre Commerciale), 29 marzo 1995 (PACE) (UNILEX). El litigio envuelve a la Cámara Agraria Provincial de Guipuzcoa, como compradora, y a André Margaron como vendedor. La Cámara compró 10.000 toneladas de maíz para uso alimentario de animales a finales de 1991. Resultó que el vendedor entregó las mercancías, pero la Cámara no pagó el precio, por lo que el primero le demandó ante los tribunales franceses. En primera instancia, la Cámara fue condenada a pagar el precio pero no los intereses. En apelación, la Cámara alegó que el precio del contrato de compraventa había sido modificado por acuerdo de las partes en una reunión celebrada en Navarra el 25 (o 26) de septiembre de 1991 y que si bien el precio inicial era de 0,16 francos franceses por kilo, se acordó un precio de 0,14. A estos efectos la Cámara presentó dos testigos, un agricultor y un veterinario, que atestiguan que el precio acordado era el que el comprador indica. El tribunal entiende que si bien la Convención permite la modificación del contrato, que en este caso todo apunta a que dicha modificación no se ha producido. Que además la modificación de un precio de venta no puede resultar de un ambiente general de una reunión; que el vendedor envió las facturas con posterioridad a la reunión sin que el comprador se quejase por el precio y, por último, que cuando el vendedor reclamó el pago, tampoco el comprador respondió. En definitiva condena al comprador al pago del precio reclamado por el vendedor y al pago de los intereses que, en opinión del tribunal, se computan desde el día en que las facturas debieron haber sido pagadas. 
El Art. $29^{\circ} \mathrm{CV}$, al indicar que «el contrato podrá modificarse o extinguirse» engloba en su texto tanto a la mera variación de alguno de los términos del contrato sin que la misma implique una extinción total del mismo, sino solo una modificación en su contenido (novación modificativa), y a la total extinción del contrato, independientemente de si ésta es seguida por una nueva obligación (novación extintiva) o no ${ }^{85}$. En el caso de la novación extintiva seguida de una nueva obligación, si se produce el cambio de objeto y éste queda excluido de la Convención, ésta no podrá aplicarse a la nueva obligación ${ }^{86}$.

Es posible que las partes acuerden que sólo valdrá una modificación o extinción escrita de los términos del contrato o del contrato mismo, por lo que cualquier modificación oral se considerará carente de valor (Art. 29.2 CV). Se trata, en consecuencia, de hacer inoperante (con el

85 En cuanto a las consecuencias de esa extinción, creemos que se pueden aplicar analógicamente los artículos $81^{\circ}$ et seq de la Convención. Asimismo, sobre la base de entender aplicables los principios generales de la Convención, Schlechtriem, en Caemmerer, von - Schlechtriem, Kommentar zum Einheitlichen UN-Kaufrecht, München, $1990, \$ 4$, p. 255. El laudo de la Cámara de Comercio Internacional (en adelante, ICC) 7331/94 (PACE) (UNILEX), ha indicado que lo que hemos caracterizado aquí como novación extintiva no se regula por la Convención de Viena de 1980 sino por el derecho nacional que resulte aplicable. Y así indica tras transcribir el Art. $29^{\circ} \mathrm{CV}$ que: "To be distinguished from a mere amendment to a prior contract is the doctrine of novation. Under the laws of all three national jurisdictions which the tribunal deems potentially relevant (France, Italy and Yugoslavia), novation cannot be presumed and requires the proof by the party alleging the existence of a novation that the original parties to the contract shared an animus novandi». Vid. el texto en Bulletin de la cour internationale d'arbitrage de la CCI, noviembre, 1995, vol. 6, núm. 2, p. 73 y ss.; también publicada y comentada por Hascher, en Journal du droit international, 1995, núm. 4, p. 1001 y ss..

86 Por ello resulta muy acertada la decisión del LG Aachen, 14 mayo 1993 (Alemania) (PACE) (UNILEX), que ha aplicado las normas de la Convención relativas a los derechos que asisten al vendedor por incumplimiento del comprador y ello aun cuando las partes tras un primer incumplimiento del contrato acordaron (settlement agreement) que el vendedor renunciaría a cualquier acción contra el comprador si éste aceptaba las mercancías y pagaba parte del precio en una determinada fecha; pasado este término, y ante el segundo incumplimiento del comprador, el vendedor demandó sus derechos y acciones bajo la Convención en función del acuerdo original. El tribunal indicó que el comprador había incumplido sus obligaciones y aplicó las reglas de la Convención (por tanto, insinuando la aplicación al segundo acuerdo, lo que se reafirma al indicar que la Convención no se ocupa de la validez del mismo). 
límite representado por la doctrina de los propios actos) cualquier modificación del contrato que no se haya realizado por escrito, si el contrato incluye una estipulación que exija su modificación por ese medio. Se reconoce, pues, la facultad de las partes contratantes para disciplinar sus relaciones de obligatoriedad en la forma que estimen más conveniente. No obstante este reconocimiento, el legislador uniforme no parece ajeno a la realidad en la que se mueve la práctica comercial internacional, donde no es del todo infrecuente que, a pesar de la existencia de una cláusula de ese tipo, se produzcan modificaciones del contrato verbalmente o mediante actuaciones de las partes contratantes. Por ello, pese a la existencia de una cláusula exigiendo la modificación por escrito - cláusulas que en el common law reciben el nombre de No Oral Modification clauses (NOM clauses) ${ }^{87}$-, serán eficaces las modificaciones realizadas mediante actuaciones concluyentes en la medida en que una parte haya confiado en la actuación realizada por la otra ${ }^{88}$.

Una cierta ayuda a la hora de determinar esa actuación y esa confianza (reliance) es proporcionada por los arts. $8^{\circ}$ y 16.2.b) $\mathrm{CV}$, que acoge el principio de que nadie puede ir en contra sus propios actos. Esta inadmisibilidad, se ha dicho, constituye técnicamente un límite del ejercicio de un derecho subjetivo o de una facultad, derivado del principio de la buena fe, y particularmente de la exigencia de observar, dentro del tráfico jurídico, un comportamiento coherente ${ }^{89}$.

87 «Ninguna modificación ni adición al presente Contrato se considerará válida a menos que la misma se realice por escrito y sea firmada por los representantes autorizados de ambas partes". Esta NOM clause corresponde al litigio Graves Import Co. Ltd. and Italian Trading Company $\nu$. Chilewich Int'l Corp., (PACE) (UNILEX); 1994 WESTLAW 519996 (S.D.N.Y.); 1994 U.S. Dist. LEXIS 13393.

88 Reconocen varios comentaristas problemas en torno a qué actuaciones serán suficientes: Hilman, "Article 29 (2) of the United Nations Convention on Contracts for the International Sale of Goods: A New Effort at Clarifying the Legal Effect of "No Oral Modification" Clauses", en Cornell international law journal, New York, 1988, núm. 21, p. 459; Herber - Czerwenka, "Internationales Kaufrecht", op. cit., p. 142; DateBah, en Bianca y Bonell, (coord.), Commentary, op. cit., p. 243 y ss. En opinión de este autor, no se especifica el tipo de conducta que determina que la parte contratante no pueda alegar la estipulación que exige que toda modificación o extinción por mutuo acuerdo se haga por escrito. Esto implica que existe una flexibilidad, o vaguedad, que produce un cierto grado de incertidumbre en la aplicación del Art. $29^{\circ} \mathrm{CV}$.

89 Así, Díez-Picazo, La doctrina de los propios actos, Barcelona, 1963, p. 193 y ss. 
En suma, la Convención consagra, en el Art. 29.2, el principio de seguridad en el comercio internacional al impedir que una de las partes contratantes vea frustradas sus expectativas a la ejecución del contrato bajo unos determinados términos cuando confió en la modificación operada verbalmente por su contraparte. Expectativas que se concretan en la circunstancia de la realización de alguna actuación o de algún acto que manifiesta una modificación en los términos del contrato escrito (requisito que exige alguna actuación positiva, objetiva y fácilmente constatable) y en la confianza en la modificación operada. Confianza que se basa en una creencia "razonable» en la modificación que debe materializarse en algún tipo de acto o actuación ${ }^{90}$.

\section{Responsabilidad precontractual}

No existe en la Convención ninguna norma o principio que imponga una responsabilidad contractual a una de las partes como consecuencia de su conducta durante la fase de negociaciones ${ }^{11}$. Éste puede decirse que es el punto de vista que ha tenido más aceptación en la doctrina uniforme, que entiende que el rechazo a reglamentar esta cuestión es demostrativo de la voluntad deliberada del legislador uniforme por abandonar la regulación de la responsabilidad precontractual al derecho interno que resulte aplicable ${ }^{92}$.

90 Es interesante destacar la distinta orientación que se sigue en el ICC Model International Sale Contract (Manufactured Goods Intended for Resale), final Draft 17 March 1997 (ICC, Doc. núm. 470-9/16) en las condiciones generales. En concreto el Art. 1.5 indica que cualquier modificación del contrato habrá de acordarse y probarse por escrito. No obstante, se establece como excepción la de que nadie puede ir contra sus propios actos, en una manera muy similar a la formulada por el Art. 29.2 CV.

91 Se rechazó durante la Conferencia Diplomática una propuesta de la antigua República Democrática Alemana de introducir un principio general de responsabilidad precontractual para cubrir aquellos casos en que una de las partes, basándose en la confianza del buen fin de las negociaciones, había gastado sumas considerables antes del abandono de las negociaciones por su contraparte (A/CONF.97/C.1/SR.11, en A/CONF.97/19, p. 317 y ss.).

92 Por todos, Schlechtriem, Uniform Sales Law. The UN-Conventions on contracts for the international sale of goods, Vienna, 1986, p. 57. 
No obstante, se debe indicar que existen dos disposiciones que sancionan al oferente en dos situaciones muy puntuales y por las cuales se le impide revocar su oferta, bien cuando es irrevocable (Art. 16.2.a) $\mathrm{CV}$ ) o bien cuando el destinatario confiaba en la irrevocabilidad de esa declaración y ha actuado basándose en ella (Art. 16.2.b) CV). Se trata, pues, de impedir que el oferente revoque cuando no puede hacerlo, bien porque ha concedido a su oferta el carácter de irrevocable, bien porque se han creado ciertas expectativas en el destinatario de la oferta que le hacen realizar algún tipo de actuación en relación a la misma. La ratio de estas disposiciones se orienta claramente a impedir, de un lado, al oferente una actuación contraria a la buena fe: revocación de una oferta que en sí misma es irrevocable; y, de otro lado, a proteger las expectativas creadas en el destinatario de la oferta. En ambos casos, el oferente se verá constreñido a la perfección del contrato si el destinatario acepta, lo que no sucede en el resto de las hipótesis de responsabilidad, donde únicamente pueden buscarse pretensiones indemnizatorias y de reparación del daño.

\section{Nota conclusiva}

Luego de este breve recorrido por la parte II de la Convención de Viena, dedicada a la Formación del Contrato, para muchos la zona neurálgica de la regulación del contrato de compraventa internacional de mercaderías, no nos queda duda que la Convención de Viena es uno de los más finos productos elaborados en una tavolo di lavoro, como diría el maestro italiano Messineo, y, además, uno de los más valiosos instrumentos que conforman el derecho uniforme del comercio internacional. 